\title{
In situ syntheses of semiconducting nanoparticles in conjugated polymer matrices and their application in photovoltaics.
}

\begin{abstract}
Hybrid solar cells based on conjugated polymers and inorganic semiconducting nanoparticles combine beneficial properties of organic and inorganic semiconductors and are, therefore, an exciting alternative to pure organic or inorganic solar cell technologies. Several approaches for the fabrication of hybrid solar cells are already elaborated and explored. In the last years routes have emerged, where the nanoparticles are prepared directly in the matrix of the conjugated polymer. Here, the conjugated polymer prevents the nanoparticles from excessive growth and thereby makes additional capping agents obsolete. This review focuses on in situ preparation methods of inorganic semiconducting nanoparticles in conjugated polymers in view of applications in hybrid solar cells. The details, advantages and disadvantages of the different in situ methods are critically examined and put in comparison to the classical route where pre-synthesized nanoparticles are used. Various key factors influencing the solar cell performance as well as future strategies for increasing the overall efficiency of hybrid solar cells prepared via in situ routes are discussed.
\end{abstract}

Keywords

Inorganic-organic hybrid solar cell $\bullet$ Nanocomposite $\bullet$ OPV

(C) 2013 Thomas Rath et al., licensee Versita Sp. z o. o.

This work is licensed under the Creative Commons Attribution-NonCommercialNoDerivs license (http://creativecommons.org/licenses/by-nc-nd/3.0/), which means that the text may be used for non-commercial purposes, provided credit is given to the author.
Thomas Rath ${ }^{1 *}$ Gregor Trimmel ${ }^{1,2}$

1Institute for Chemistry and Technology of Materials, Graz University of Technology, Stremayrgasse 9, 8010 Graz, Austria

${ }^{2}$ Christian Doppler Laboratory for Nanocomposite Solar Cells, Graz University of Technology, Austria

\section{Introduction}

The research for new and alternative materials and technologies for the supply of our society with clean energy is one of the central and most challenging tasks in today's materials science and is driven by the goal to overcome future shortage of fossil fuels and extensive emission of carbon dioxide. As the sun provides more than enough energy, efficient solar cells, prepared at low cost, could display a breakthrough in the fight against global warming and dependency on fossil primary energy carriers. In particular, organic solar cells are discussed to fulfill these requirements by providing the possibility of low cost roll-to-roll processing and using cheap and abundant raw materials. Also due to the increasing power conversion efficiencies (PCEs) of organic based solar cells they became more and more attractive in the last years and in 2012 the psychologically important PCE value of $10 \%$ was exceeded [1-3]. Additionally, the lifetime of organic based solar cells already became quite competitive [4].

Hybrid solar cells based on conjugated polymers and inorganic semiconducting nanocrystals are an exciting alternative to pure organic or inorganic solar cell technologies as they combine beneficial properties of organic and inorganic semiconductors, and thus, have the conceptual potential to reach efficiencies comparable to inorganic solar cells in the future. Hybrid solar cells exhibit most advantages of organic solar cells: they can be produced more energy efficiently avoiding high temperature processes, they can be produced fast using rollto-roll printing and coating technologies, and they make use of the high absorption coefficients of organic polymers. Moreover, additional benefits are expected from the inorganic part like high charge carrier mobilities and the possibility to tune the optical and electrical properties of the acceptor phase by tailoring the size, shape and composition of the nanostructures.

Today, the highest efficiencies reported for hybrid solar cells are around 4\% [5-8], which is still far away from the efficiencies of above mentioned technologies, but the progress in PCE in the last years and the conceptual advantages make it more and more realistic to approach the long-term goal of cheap, efficient and stable hybrid solar cells in future.

The concept of hybrid solar cells was introduced by Greenham et al. already in 1996 [9]. They studied charge separation and transport in nanocomposites consisting of CdS or CdSe nanoparticles and poly[2-methoxy-5-(2-ethylhexyloxy)1,4-phenylenevinylene] (MEH-PPV) and showed for the first time that quantum efficiencies of solar cells using these nanocomposite layers are improved compared to solar cells with active layers consisting of pristine MEH-PPV. This concept was further explored in the following years and in 2002 PCEs of 
poly(3-hexylthiophene) P3HT/CdSe hybrid solar cells of $1.7 \%$ were reported also by the group of Alivisatos [10]. The improvement in efficiency was mainly achieved by replacing nanoparticles with nanorods and further tuning the band gap by varying the nanorods' radius. The use of nanorods increased the efficiency by reducing the number of particle interfaces, which facilitates charge carrier transport. This illustrates the importance of tuning the shape of the nanostructures for hybrid solar cell applications. Furthermore, the importance of ligand exchange, which was already recognized at this initial stage of the development, is discussed in these two early papers. The long chained capping agent trioctylphosphineoxide (TOPO) was partly removed by washing with methanol and treatment with pyridine.

Motivated by these pioneering works research on hybrid solar cells was pursued and, especially in recent years, the interest of scientists in this class of materials grew rapidly, which is also reflected by the increasing number of publications and especially reviews on hybrid solar cells highlighting the dynamic progress of this technology [11-25].

Due to the large number of possible combinations of inorganic semiconductor nanoparticles with conjugated polymers, it is possible to choose both components for the active layer in such a way that they absorb complementary parts of the solar spectrum. Thus, both components can absorb light, which leads to improved charge carrier generation. Light harvesting in the near infrared part of the solar spectrum is also possible by selecting suitable semiconductors such as $\mathrm{PbSe}$ or $\mathrm{PbS}$ nanoparticles [26,27]. Additionally, the band gaps of these materials can easily be tuned by varying the particle size due to the quantum confinement effect [28]. Moreover, compared to fullerene based materials, hybrid solar cells based on inorganic nanoparticles and conjugated polymers have the advantage of being structurally more flexible by using dot, rod, or tetrapodshaped inorganic semiconducting nanostructures. Thus, the morphology of the active layer can be tailored towards efficient charge separation and charge transport.

Roughly in the last 15 years, various inorganic materials in combination with conjugated polymers have been reported for the preparation of hybrid solar cells. Prominent examples are wide band gap metal oxides like titanium dioxide [29] or zinc oxide [30], medium bandgap materials like cadmium sulfide [31], selenide $[8,32,33]$ or telluride [34], copper indium sulfide [35] and selenide [36], as well as low band gap materials like lead sulfide [6], or selenide [37]. Recently, also other abundant and non-toxic materials like $\mathrm{SnS}_{2}$ [38], $\mathrm{FeS}_{2}$ [39] or $\mathrm{Bi}_{2} \mathrm{~S}_{3}$ [40] as well as silicon nanoparticles [41] have been researched concerning the incorporation in hybrid solar cells. However, it should be noted that, compared to fullerenepolymer solar cells, only a fraction of manpower has worked on hybrid photovoltaics, especially when the manifold possibilities of material combinations are taken into account. For only few of these material combinations more than 10 publications can be found.

Beside the research on new material combinations, a lot of research effort was dedicated to explore new routes for the preparation of such hybrid materials for solar cell applications. In all routes, a good control of the synthetic process is a prerequisite for the achievement of high PCEs, as impurities in the nanocomposite layers, such as capping agents or byproducts of the nanoparticle formation, and traps, caused by defects in or at the surface of the nanoparticles, would impede charge carrier generation and transport in the composite.

These synthetic routes can be roughly divided into three classes depicted in Figure 1: 1) In the classical approach, the
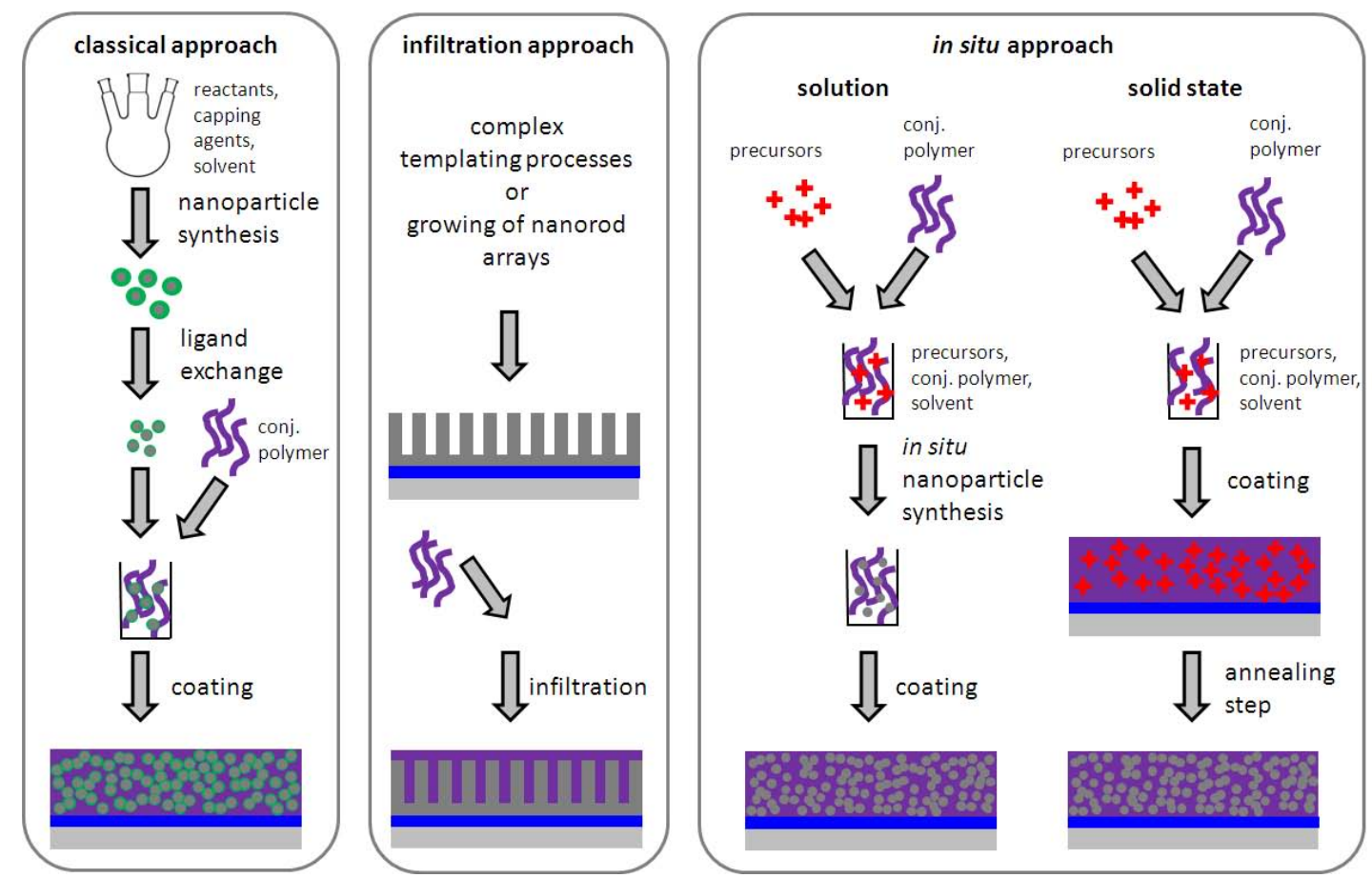

Figure 1. Routes towards the preparation of nanocomposite layers for hybrid solar cells. 
inorganic nanoparticles are synthesized in a first, separate step. Then the nanoparticles are purified and usually subjected to a ligand exchange step. After that, they are dissolved together with the polymer giving the coating solution for the active layer. 2) In the infiltration approach preformed inorganic nanostructures are infiltrated with an organic polymer. Thereby, highly porous, or even highly ordered mesoporous inorganic skeletons obtained by templating processes or nanorod arrays can be incorporated in hybrid solar cells. Thus, in this approach there are also no ligands between the inorganic and organic phase. However, many routes use higher temperature steps and/or long reactions times and, therefore, are often not suited for roll-to-roll processes. 3) In the in situ approach the nanoparticles are formed directly from precursors in the conjugated polymer matrix. Having a suitable precursor, this approach is the conceptually simplest one, as the synthesis of the nanostructures is carried out already in the active layer or the coating solution omitting an extra process for the generation of the inorganic nanostructures and avoiding stabilizing ligands. During the reaction, the polymer acts as capping agent and prevents extensive particle growth. During the last years, different new in situ approaches have emerged which gave us the motivation to review the dynamic progress of this concept.

The focus of this review is set on the in situ formation of inorganic nanostructures in a conjugated polymer matrix for hybrid photovoltaics. Advantages and drawbacks of this method will be discussed in detail in the next sections.

Hybrid solar cells with absorber layers consisting of conjugated polymers and inorganic semiconducting nanoparticles have device architectures similar to polymer/ fullerene solar cells. The devices are prepared either in the classical or the inverse geometry, see Figure $2 \mathrm{~A}$ and $\mathrm{B}$, respectively. In the classical geometry a glass/ITO substrate is typically coated with a poly(3,4-ethylenedioxythiophene)-poly(styrenesulfonate) (PEDOT:PSS) layer followed by the absorber layer, an interlayer and a metal electrode. In the inverse geometry the different layers are prepared in the following sequence on the glass/ ITO substrates: interlayer (e.g. metal oxide) / absorber layer / interlayer (e.g. PEDOT:PSS) / metal electrode.

\section{In Situ Preparation Routes}

\subsection{General aspects}

Before covering the in situ routes in more detail, we compare them to the classical and infiltration approach and, thereby, also shortly discuss the advantages and disadvantages of these concepts.

\subsubsection{In situ versus classical approach}

The in situ route has, on the first glance, numerous similarities to the classical approach in terms of formed nanostructures, nanoparticle sizes, morphology of the nanocomposite, processing, and device assembly. However, there are distinct differences between these two approaches. The in situ approach intends to overcome the problems associated with capping ligands which usually are used for the nanoparticle synthesis in the classical route.

Typically capping ligands, like long chained amines or bulky phosphines or phosphine oxides, prevent particle agglomeration during synthesis and control the particle growth and shape. This has the advantage that it is possible to obtain highly defined nanoparticles with narrow particle size distribution and with adjustable size and shape. Such flexibility is usually not achievable with the in situ route. However, the ligands interfere with the elemental processes in solar cells as they influence both, charge dissociation as well as charge transport. Usually, these ligands act as a barrier for both steps. Therefore, removing or exchanging the bulky ligand molecules to smaller ones is crucial prior to solar cell fabrication. As a consequence immense effort was put in the development of approaches towards ligand exchange with e.g. pyridine [33,42], other "smaller" amines, such as butylamine [43], or thiols such as t-butylthiol [44,45].

Alternatively, new functional, smart ligands were introduced bearing thermally cleavable chains to partly remove the capping sphere [46] or conjugated side groups to enhance charge dissociation and charge transport $[47,48]$. In the first case, e.g. the thermal cleavage of a t-BOC ( $\mathrm{N}$-t-butoxycarbonyl) moiety of a t-butyl $\mathrm{N}$-(2-mercaptoethyl)carbamate ligand reduces the distance between the nanoparticles and also between the
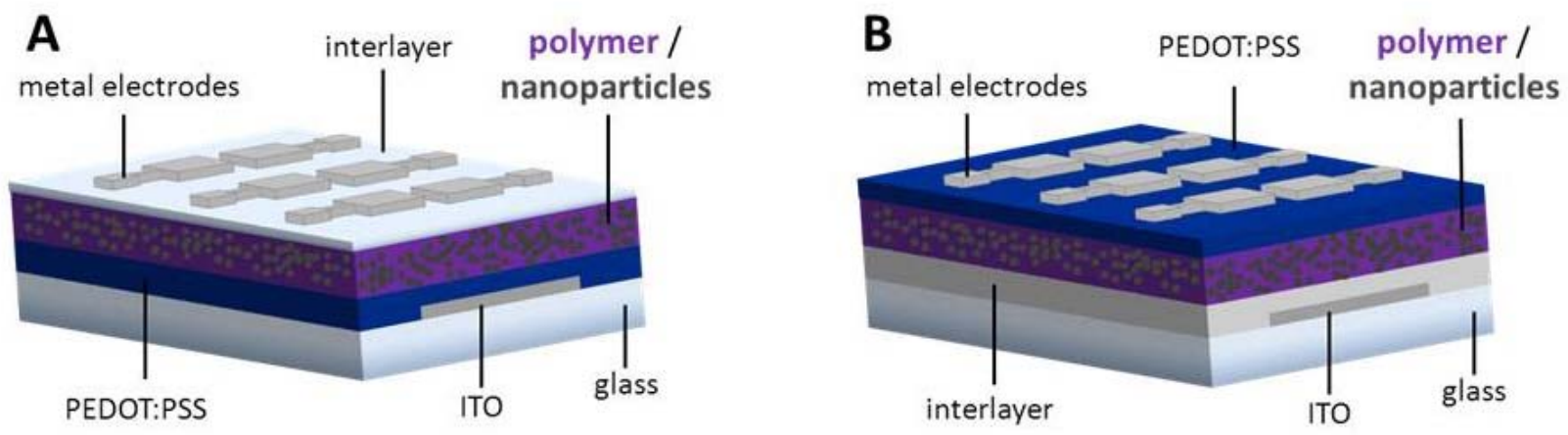

Figure 2. Typical device architectures of polymer/nanoparticle hybrid solar cells in A: normal and B: inverse geometry. 
nanoparticles and the conjugated polymer matrix [46]. In the latter case mainly conducting oligothiophenes are used as capping agents, which improves the electronic properties of the hybrid nanoparticle polymer interface compared to commonly used non-conductive cappers. A disadvantage thereby is, however, the often laborious synthesis of conjugated capping agents.

The simple exchange of the long chained capping agents to shorter ones has typically a negative effect on the solubility of the nanoparticles and thus also on the morphology and quality of the prepared nanocomposite layers. Due to the incompatibility of solvents required to dissolve nanoparticles and conjugated polymers, often mixtures of solvents are used [33], which in turn can negatively influence nanoparticle dissolution and distribution as well as polymer chain orientation in the nanocomposite layer [49].

Besides the ligand exchange processes, also other strategies were explored and e.g. a process for removing of excess capping agent by using hexanoic acid was introduced by Zhou et al. [50]. By this treatment, the capping ligand (hexadecylamine) forms a salt with the hexanoic acid, which is much more easily dissolved in the supernatant. A further advantage of this process is that a good solubility of the nanoparticles is retained, which allows a higher loading of nanoparticles.

Nevertheless, all these approaches require further synthesis or modification steps in addition to the actual nanoparticle synthesis.

In contrast to these approaches, the in situ approach yields into nanostructures without capping agents directly in intimate contact with the conjugated polymer. Additionally, particle to particle distance is typically shorter facilitating charge transport. A comparison by Reynolds et al. [31] impressively demonstrates the difference between three P3HT/CdS layers prepared using a) a classical approach with oleic acid without ligand exchange step b) the same approach but with exchange of oleic acid for hexylamine and c) an in situ approach using a cadmium ethyl xanthate precursor (see Scheme 1C). The morphology of these samples clearly exhibit large variations in the distribution of the inorganic phase, as shown in the TEM images of these three samples in Figure 3. The nanoparticles in TEM image (a) are capped with oleic acid and are well separated from each other. No direct contact of the inorganic cores is possible. In the case of the hexylamine capped nanoparticles (b) the inter-particle distance is much smaller in the nanocomposite layer and some percolation pathways seem to be present.

The TEM image of in situ prepared CdS nanoparticles in a P3HT matrix (Figure 3c) exhibits that the nanoparticles have intimate contact and are partly aggregated to bigger units.

These differences in inter-particle distances and agglomeration behavior have a dramatic influence on the electronic properties of the nanocomposite layers, which was demonstrated by transient absorption spectroscopy (see Figure 4). The agglomerated CdS-structures obtained by the in situ approach lead to improved charge separation efficiency at the hybrid interface compared to nanocomposites prepared via the classical route, as clearly shown in the transient absorption

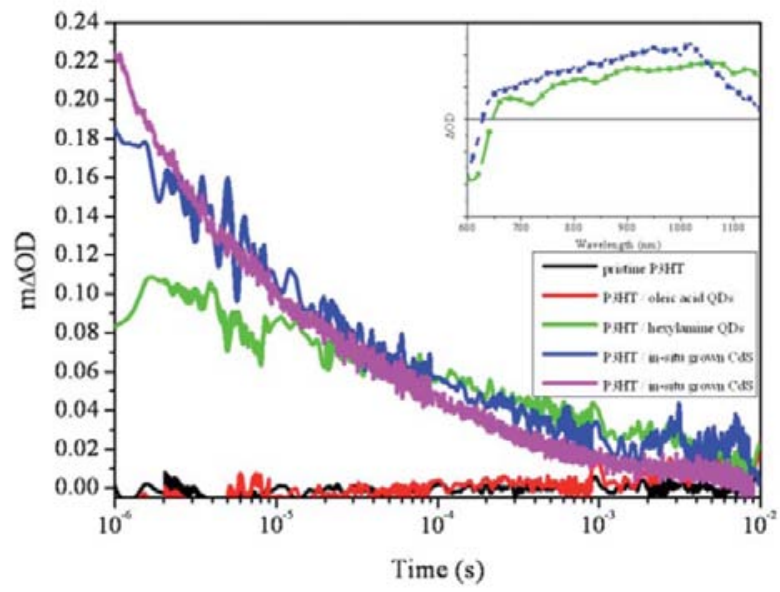

Figure 4. Transient absorption decays for films of pristine P3HT (black), P3HT/CdS nanoparticles with oleic acid (red) or hexylamine (green) capping ligands, and two P3HT/in situ grown CdS films of different ratios (blue and magenta). Excitation was at $550 \mathrm{~nm}$ and $\sim 60 \mathrm{mJcm}^{-2}$ and the absorption was probed at $980 \mathrm{~nm}$. Inset: Transient absorption spectrum at $10 \mathrm{~ms}$ for a P3HT/in situ grown CdS film (blue) and for a P3HT/hexylamine nanoparticle film (green showing a ground state bleach and the $\mathrm{P} 3 \mathrm{H} \mathrm{T}^{+}$polaron peak. Reprinted with permission from [31]. Copyright (2012) The Royal Society of Chemistry.
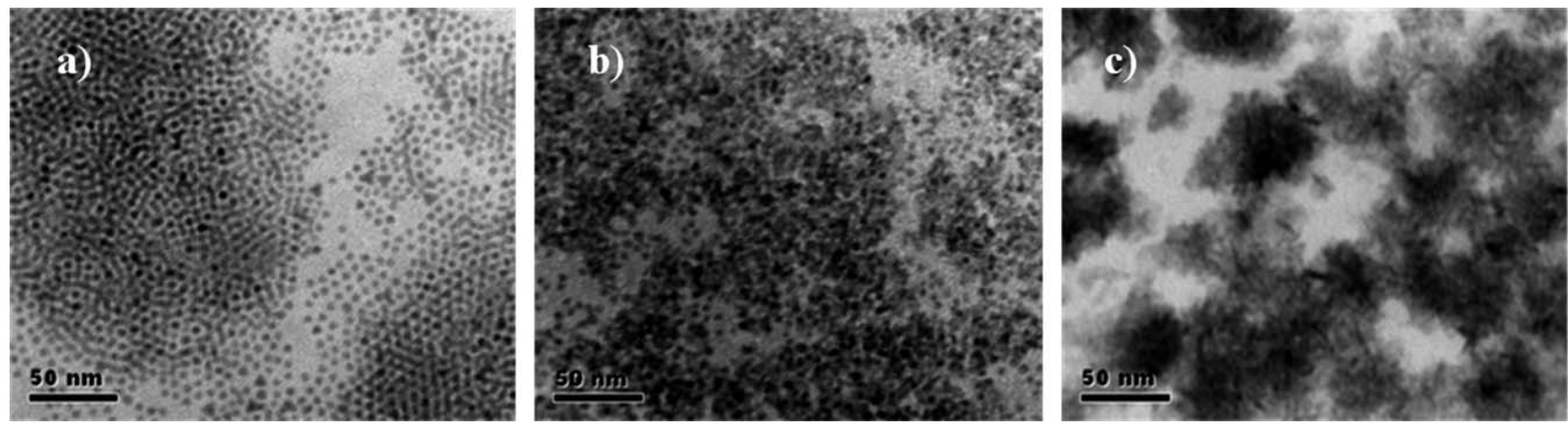

Figure 3. Top-down TEM images of equivalently loaded P3HT/CdS blends: a) shows CdS in the form of nanoparticles capped with oleic acid; b) shows CdS in the form of nanoparticles capped with hexylamine; c) shows in situ grown CdS. Darker regions are the inorganic component. Scale bars are $50 \mathrm{~nm}$. Reprinted with permission from [31]. Copyright (2012) The Royal Society of Chemistry. 
decays in Figure 4. The capping ligands lower or, in the case of oleic acid, even impede the polaron formation, while the improved inter-particle coupling and agglomeration to bigger units in in situ prepared nanocomposite layers additionally fosters the generation of long-lived charges by the fact that electrons can move away from the dissociation sites [31].

In spite of these clear advantages of the in situ approach, there are also some drawbacks. Because the nanoparticle formation takes place in presence of the conjugated polymer, the synthesis has to be carried out at moderate temperatures which are not harming the structure and the optoelectronic properties of the polymer. Together with the high viscosity of polymer melts and solutions, crystal growth is strongly influenced and, therefore, cannot be tuned so easily to vary size and shape of the nanostructures compared to the classical route. Additionally, this might result in a lower crystallinity and higher defect density influencing the electronic properties of the inorganic phase in a negative way.

As a last point, the in situ approach generates by-products which might cause problems if not completely removed from the material. Outgassing of volatile by-products could generate pores in the absorber layer during the solid state in situ approach. However, the nanocomposite layers obtained by some of the methods are impressively homogenous and flat [35].

\subsubsection{In situ versus infiltration approach}

Infiltration of preformed inorganic nanostructures has the striking advantages that the complete inorganic acceptor phase is connected to the right electrode, thus, no dead ends in charge transport are present. Examples of such approaches are the preparation of $\mathrm{TiO}_{2}$ nanorods [51] or of highly ordered $\mathrm{TiO}_{2}$ network structures [52]. In addition, using this approach, capper free structures can be obtained. These highly ordered and ligand free structures are hardly accessible with either the classical or the in situ approach. However, the infiltration of viscous polymers into small pores might cause problems.

All in all, compared to the in situ approach more complex processing steps are needed which might be a limiting factor in future applications regarding fast and cheap production.

\subsubsection{General requirements for an in situ approach}

The in situ formation of inorganic nanostructures can be done in solution or without solvent via a solid state reaction directly in the polymer matrix using various precursor materials. For developing a suitable in situ route some general aspects have to be considered.

1. The precursor should be converted to the desired semiconducting nanostructures using experimental conditions compatible with conjugated polymers (low temperatures, no reactions of precursors and side products with the polymer, etc.).

2. The thereby formed side products should be removable from the material - thus they should be volatile or extractable.

3. The precursor and the polymer should be soluble in the same solution. In the view of the huge amount of available apolar conjugated polymers, apolar precursors are favorable to get homogeneous solutions of both components. In the case of polar precursors, it is possible to use solvent mixtures or conjugated polymers with polar side groups. Examples of polar and apolar precursors are summarized in Scheme 1.

4. For industrial realization, the precursor as well as the coating solution should be stable and of course the precursor should be easy to prepare and cheap.

During the last years, in situ routes mainly for metal chalcogenides have been introduced. Scheme 1 gives an overview over the most prominent in situ approaches grouped in polar and apolar precursors. Mainly transition metal oxides, i.e. $\mathrm{ZnO}$ and $\mathrm{TiO}_{2}$ and metal sulfides have been targeted so far.

Looking at Scheme 1 only a limited number of inorganic semiconductors have been prepared by in situ methods. Regarding the organic polymers used so far, a similar picture can be observed. Despite the huge variety of conjugated polymers developed during the last decade for organic photovoltaics, only a few classes have been tested in hybrid solar cells prepared via an in situ approach. The most important structures are shown in Scheme 2.

In the following, the different methods developed for the preparation of metal oxides, sulfides, selenides and tellurides in conjugated polymer matrices are discussed and their advantages and drawbacks are highlighted.

\subsection{In situ approaches to metal oxide- conjugated polymer hybrid materials}

Transition metal oxides have been researched as acceptor materials in inorganic-organic solar cells. In particular, $\mathrm{TiO}_{2}$ and $\mathrm{ZnO}$ are of special interest as they are easy to prepare and their properties are well-known. Both are UV-absorbers, and thus, act mainly as acceptor component in hybrid solar cells. They can be synthesized under various experimental conditions including low temperature routes and, in addition, it is possible to create nanostructures. Moreover, the optical and electronic properties can be tuned by dopants and by modification of their surface. $\mathrm{TiO}_{2}$ and $\mathrm{ZnO}$ can have excellent charge transport properties, but these strongly depend on the defect densities and surface states both determined by the stoichiometry and the processing conditions [53]. A first review on metal oxide/polymer hybrid solar cells by Bouclé et al. gives a good introduction on the interplay of morphological aspects with optical/electronic properties of the material [54]. The borderline between typical metal oxide polymer hybrid solar cells and dye sensitized solar cells blurs in metal oxide/dye/conjugated polymer combinations and other "mixed hybrid systems" which are also heavily researched [55]. For both $\mathrm{TiO}_{2}$ and $\mathrm{ZnO}$, in situ routes have been introduced during the last 10 years.

\subsection{1. $\mathrm{TiO}_{2}$-conjugated polymer hybrid materials}

The high reactivity of titanium-alkoxides towards moisture to form $\mathrm{TiO}_{2}$ can be used elegantly for in situ formation of an inorganic network at room temperature or modest annealing temperatures (cf. Scheme 1A). This approach was first introduced 


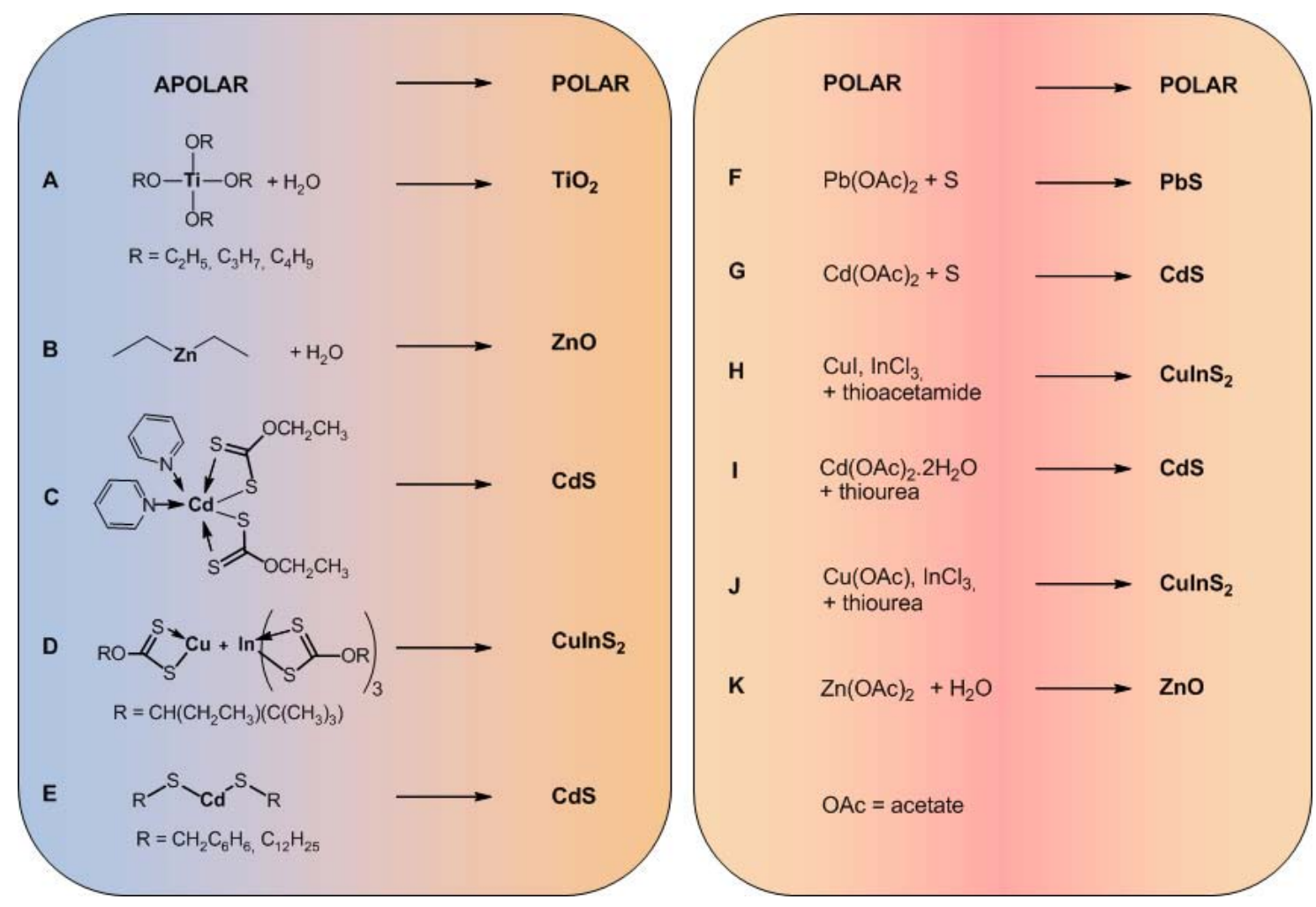

Scheme 1. Precursors used for in situ syntheses.

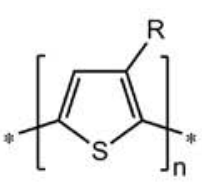

P3HT: $\quad \mathrm{R}=$ hexyl

P30T: $R=$ octyl

P3EBT: $\mathrm{R}=$ * $\overbrace{\mathrm{O}}^{\mathrm{O}}$ copolymers:

P3HT-E: $\mathrm{R}=$ hexyl, acetoxyethyl

P3HT-OH: R = hexyl, 6-hydroxyhexyl

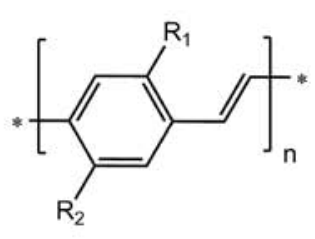

PPV: $\quad \mathrm{R}_{1}=\mathrm{R}_{2}=\mathrm{H}$

MEH-PPV: $\mathrm{R}_{1}: \mathrm{OCH}_{3}, \mathrm{R}_{2}: *-\mathrm{O}$

MDMO-PPV: $\mathrm{R}_{1}: \mathrm{OCH}_{3}, \mathrm{R}_{2}: *-\mathrm{O}^{\text {Y }}$
PSiF-DBT<smiles>CCCCCCc1cc(C)[se]c1C(C)(C)C</smiles>

P3HS

Scheme 2. Most important polymers used for the in situ preparation of hybrid solar cells.

by van $\mathrm{Hal}$ et al. by coating a layer of poly[2-methoxy-5-( $3^{\prime}, 7^{\prime}$ dimethyloctyloxy)-1,4,-phenylene vinylene] (MDMO-PPV) and titanium(IV) isopropoxide from a homogeneous tetrahydrofuran solution. This precursor film was subsequently hydrolysed in air in the dark to form $\mathrm{TiO}_{2}$-nanostructures and afterwards dried under reduced pressure [29]. The photoinduced electron transfer from MDMO-PPV to the $\mathrm{TiO}_{2}$ nanoparticles was proven by optical spectroscopy in contrast to analogous prepared $\mathrm{ZrO}_{2} /$ MDMO-PPV layers where no electron transfer was observed. The obtained PCEs reached values of approx. 0.19\%. In a subsequent study, Slooff et al. compared the properties of $\mathrm{TiO}_{2} /$ MDMO-PPV and $\mathrm{TiO}_{2} / \mathrm{P} 3 \mathrm{OT}$ (poly-(3-octylthiophene) [56]. Both material systems showed a drastic increase of the initial PCEs during storage in a glovebox reaching similar maximum PCEs of $0.17 \%$ and $0.22 \%$, respectively, after one day. However, during prolonged storage the performance of the MDMO-PPV based solar cells rapidly decreased whereas the polythiophene based device showed a good stability over 3 weeks in the dark.

In a follow-up study, the authors compared flat layer $\mathrm{TiO}_{2} / \mathrm{MDMO}-\mathrm{PPV}$ structures with the in situ prepared bulkheterojunction devices and studied the influence of humidity during spin coating on the performance of the solar cells [57]. A relative humidity between 40 and $50 \%$ was beneficial in the in situ route. Both types showed a similar increase of PCEs 
during storage depending on the humidity, but the flat layer devices thereby showed a slightly better performance $(0.3 \%$ versus $0.14 \%$ ). Based on external quantum efficiency (EQE) measurements on $\mathrm{TiO}_{2} / \mathrm{P} 3 \mathrm{HT}$ layers prepared by the same method showing a response in the energy range below the $\mathrm{P} 3 \mathrm{HT}$ edge, Healdermans et al. postulated a ground-state charge transfer complex from the $\mathrm{HOMO}$ of $\mathrm{P} 3 \mathrm{HT}$ to the conduction band of $\mathrm{TiO}_{2}$ [58].

Using Ti(OPPr $)_{4}[59]$ or a mixture of $\mathrm{Ti}(\mathrm{O} \mathrm{Pr})_{4}$ and a functionalized titanium alkoxide, tetrakis(9H-carbazole-9-yl-ethyl-oxy)titanium (see Scheme 3) [60], and poly(N-vinylcarbazol) (PVK) as polymer component, $\mathrm{TiO}_{2} / \mathrm{PVK}$ nanocomposites have been prepared. The authors showed a good distribution of the inorganic phase in the material but only a small photovoltaic effect was observed with negligible PCE far below $0.01 \%$ [61].

The hydrolysis and condensation of $\mathrm{Ti}(\mathrm{O} P r)_{4}$ in the solid state directly in the matrix of a conjugated polymer did not yet yield efficient photovoltaic devices. One reason might be that the crystallinity of the $\mathrm{TiO}_{2}$ phase is not high enough. In addition, in comparison to $\mathrm{ZnO}$ /polymer hybrid solar cells using diethylzinc (see below), the mass of volatile species gassing out of the film ( $4 \mathrm{~mol}$ isopropanol per $\mathrm{TiO}_{2}$ ) is much higher than in the case of $\mathrm{ZnO}$ which could also negatively effect the homogeneity of the absorber layer. However, the low quantity of the reported experimental results does not allow a final conclusion.

$\mathrm{TiO}_{2}$ /polymer hybrid materials have also been prepared by the solution in situ approach. Chang et al. use $\mathrm{Ti}\left(\mathrm{OC}_{4} \mathrm{H}_{9}\right)_{4}$ as precursor for the preparation of $\mathrm{TiO}_{2}$ nanoparticles in a solution of chlorobenzene containing either $\mathrm{P} 3 \mathrm{HT}$ or a copolymer, poly\{(3hexylthiophene)-co-[3-(6-hydroxyhexyl)thiophene]\} (P3HT-OH) [62]. The hydroxyl group of $\mathrm{P} 3 \mathrm{HT}-\mathrm{OH}$ interacts with the growing $\mathrm{TiO}_{2}$ sol-particles preventing precipitation of the nanoparticles and also leads to a homogenous distribution in the hybrid film after coating while the incompatibility of $\mathrm{P} 3 \mathrm{HT}$ with the growing $\mathrm{TiO}_{2}$ nanoparticles leads to large agglomerates and fast precipitation. Photovoltaic devices of $\mathrm{TiO}_{2} / \mathrm{P} 3 \mathrm{HT}-\mathrm{OH}$ exhibited a higher PCE value of $0.12 \%$ compared to $\mathrm{TiO}_{2} / \mathrm{P} 3 \mathrm{HT}$ devices with a PCE of $0.05 \%$ which originated mainly from differences in short circuit current $\left(\mathrm{I}_{\mathrm{SC}}\right)$ values.

Chen et al. use chlorophenol as solvent for the preparation of $\mathrm{TiO}_{2}$ nanocrystals from $\mathrm{Ti}(\mathrm{O} \mathrm{Pr})_{4}$ in the presence of $\mathrm{MEH}-\mathrm{PPV}$ $[63,64]$. The phenolic hydroxyl group interacts with the surface of the $\mathrm{TiO}_{2}$ nanoparticles and prevents agglomeration and precipitation during the sol-gel process. The resulting hybrid materials have been optically characterized, however, no data on solar cells have been presented so far.

A quite interesting approach for $\mathrm{TiO}_{2} / \mathrm{SiO}_{2}$-organic hybrid materials with covalent bonding was introduced by Lin et al. using a small PPV-type molecule bearing two ethoxy-silyl endgroups: 1,4-bis[4-(ethoxydimethylsilyl)styryl]-2,5-dioctyloxybenzene (TPV-Si), see Scheme 3 [65]. Co-hydrolysis and condensation of TPV-Si with $\mathrm{Ti}(\mathrm{O} P r)_{4}$ and $\mathrm{Si}(\mathrm{OEt})_{4}$ leads to hybrid solar cells with PCEs up to $1.09 \%$. Interestingly best results were obtained with a high amount of $\mathrm{SiO}_{2}$ as the molar fraction of $\mathrm{TPV}-\mathrm{Si}: \mathrm{TiO}_{2}: \mathrm{SiO}_{2}$ was 1:2:4.

The utilization of partially pre-hydrolysed $\mathrm{TiO}_{2}$ sols as precursor marks the borderline to the classical approach. For example such an approach was used by Wang et al. for $\mathrm{TiO}_{2} / \mathrm{PPV}$ hybrid solar cells with modest PCEs below $0.02 \%$ [66]. Pre-hydrolysed $\mathrm{TiO}_{2}$ sols have also been used for the preparation of highly ordered mesostructured $\mathrm{TiO}_{2} / \mathrm{MEH}-\mathrm{PPV}$ materials. In the presence of an amphiphilic block copolymer as templating agent, a cubic interpenetrating bi-continuous network of the donor and acceptor phase was formed. However, only efficiencies of $0.034 \%$ have been obtained [67]. Possible reasons might be the remaining structuring agent in the layer or again the low crystallinity of the nanostructures. In a subsequent paper, different block copolymers have been used as structuredirecting agents all yielding similar cubic structures. However, the interaction between the $\mathrm{TiO}_{2}$ and the MEH-PPV chains strongly depends on the type of block copolymer as analyzed by TEM and 2-dimensional-NMR studies. In the case where a direct interaction between donor and acceptor was possible also the highest PCE value of $0.082 \%$ was observed [68].

\subsubsection{ZnO-conjugated polymer hybrid materials}

$\mathrm{ZnO}$ is a very interesting material concerning solar cells, used as electrode buffer material, as transparent electrode, but also as acceptor in hybrid solar cells [69]. ZnO nanoparticles and nanostructures can be easily prepared and have good electronic properties. Like $\mathrm{TiO}_{2}$, it is an UV-absorber and does not contribute significantly to light absorption.

The most prominent in situ preparation route for $\mathrm{ZnO}$ was developed by the group of Janssen via the decomposition of
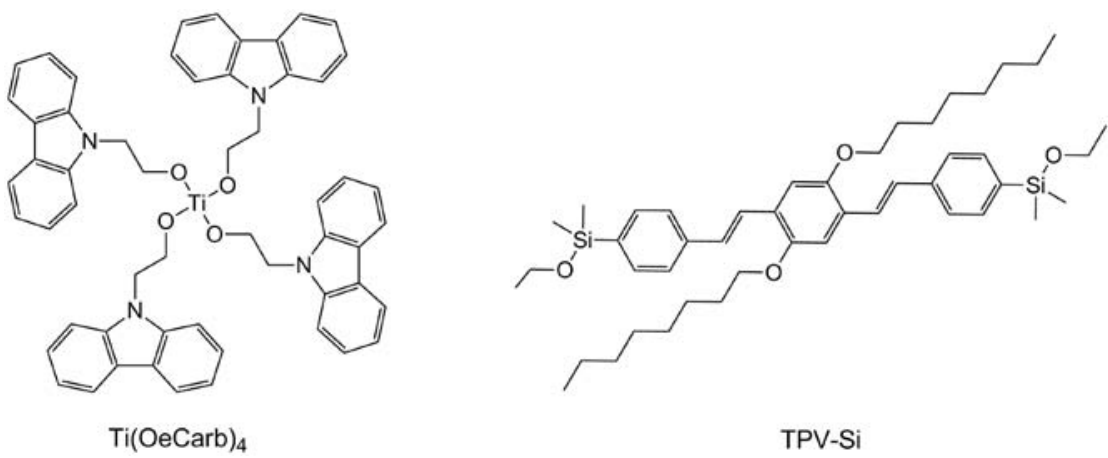

Scheme 3. Chemical strucutures of a carbazol-functionalized titanium alkoxide [60] and TPV-Si [65]. 
diethylzinc under moisture (see Scheme 1B) [70]. Using MDMOPPV as polymer phase, already promising PCEs of about $1.1 \%$ were obtained. Diethlylzinc is very sensitive to humidity and oxygen. The conversion to $\mathrm{ZnO}$ probably starts already during the spin coating process, if this step is carried out under ambient conditions, but usually an annealing step at comparatively low temperatures e.g. $110^{\circ} \mathrm{C}$ compatible with conjugated polymers is applied to enhance the crystallinity of the $\mathrm{ZnO}$ nanostructures. Interestingly, the open circuit voltage $\left(\mathrm{V}_{\mathrm{oc}}\right)$ obtained by this method with a value of $1.14 \mathrm{~V}$ was much higher than that for similar layers obtained from $\mathrm{ZnO}$ nanocrystals and MDMO-PPV by the classical route $(0.81 \mathrm{~V})$ [71].

The comparison of MDMO-PPV with $\mathrm{P} 3 \mathrm{HT}$ using the same method by Moet et al. showed that during the conversion process few of the double bonds in MDMO-PPV react leading to a slight degradation, whereas the poly(thiophene) skeleton remains unaffected during this reaction. Thus, the PCEs of P3HT-ZnO solar cells reached a value of approx. 1.4\% [72].

Oosterhout et al. thoroughly characterized the 3D-morphology of this system by electron tomography and the dependence of the photovoltaic parameters on the thickness of the active layer [30]. The solar cell parameters improved drastically by increasing the film thickness up to $100 \mathrm{~nm}$. But also thicker layers up to $250 \mathrm{~nm}$ show good performance, especially the $I_{s c}$ values remain high. The best solar cell performance was
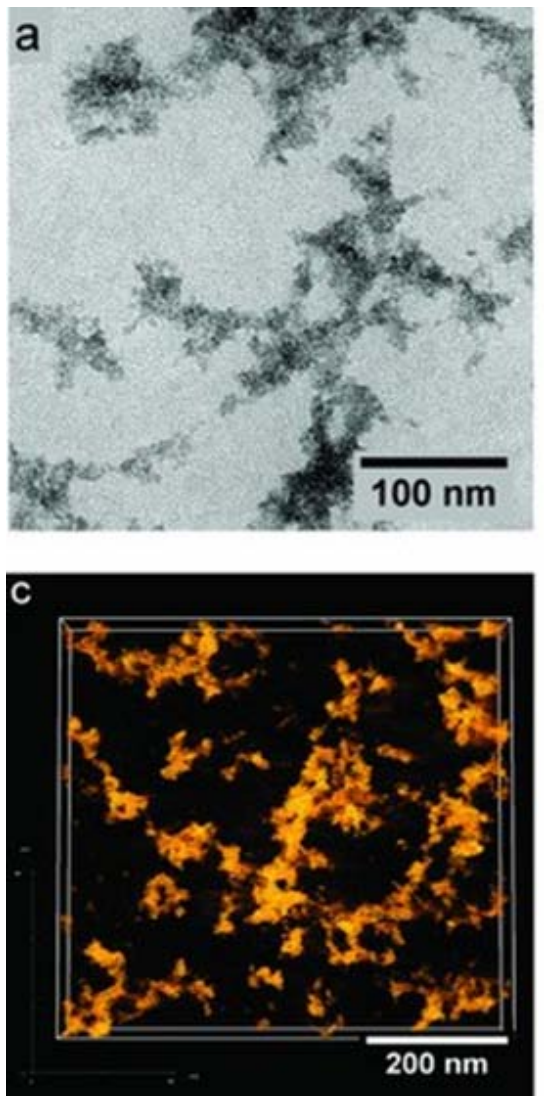

obtained from solar cells of a thickness of about $225 \mathrm{~nm}$ showing that also the nanocrystalline $\mathrm{ZnO}$ has a good connected network with reasonable charge carrier mobility. The 3-dimensional morphology of the hybrid material served as input for the development of a simulation tool using a stochastic multiscale sphere model allowing to predict the morphology obtained by varying the spin coating velocity [73]. This parameter does not only influence the thickness of the active layer but also the phase separation of the inorganic from the organic phase.

Because of the phase separation observed in the $\mathrm{ZnO} / \mathrm{P} 3 \mathrm{HT}$ hybrid layers caused by the immiscibility of the two phases, the charge carrier generation is not very efficient, whereas the large agglomerates are very efficient in charge extraction. Guided by the search for improvements of the charge carrier generation, the same group investigated a poly-3-hexylthiophene based copolymer, poly[(hexylthiophene-2,5,-diyl)-co(3-(2-acetoxyethyl) thiophene-2,5-diyl)] (P3HT-E) [74]. The more polar 2-acetoxyethyl side chains of the introduced co-monomer (amount of the comonomer: $30 \%$ ) bearing an ester functionality should improve the interaction with the polar $\mathrm{ZnO}$ phase. By comparing these new $\mathrm{ZnO} / \mathrm{P} 3 \mathrm{HT}-\mathrm{E}$ hybrid materials with the classical $\mathrm{ZnO} / \mathrm{P} 3 \mathrm{HT}$ layers, a more homogeneous distribution of the $\mathrm{ZnO}$ phase was created. The comparison of the 3D-morphologies of both materials is shown in Figure 5, exhibiting large differences in structural features and dimensions of the phase separation.
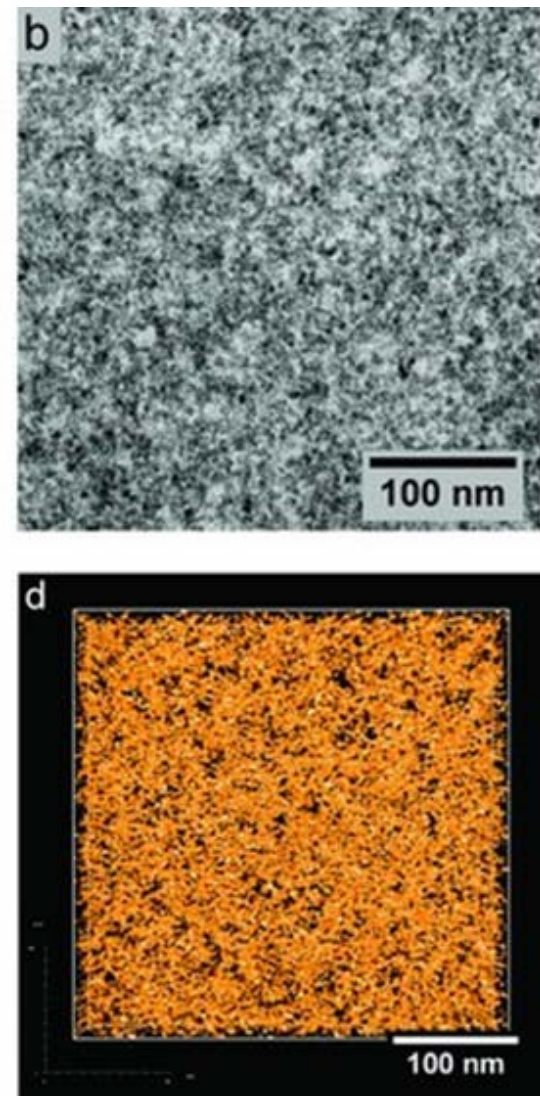

Figure 5. Comparison of the 3D-morphology of a ZnO/P3HT blend with a ZnO/P3HT-E blend. TEM images of ZnO/P3HT (a) shows larger agglomerated structures than in the case of ZnO/P3HT-E (b) which is also demonstrated by the reconstructed volumes from electron tomography, ZnO/ $P 3 H T$ (c) and ZnO/P3HT-E (d). Reprinted with permission from [74]. Copyright (2011) Wiley. 
Based on these 3D-morphologies, an enormous difference in charge carrier generation efficiency between $\mathrm{ZnO} / \mathrm{P} 3 \mathrm{HT}$ (40\%) and ZnO/P3HT-E (96\%) was calculated. Together with a sufficient connectivity this would have indicated towards an improved performance of the new system. However, the maximum PCE of the new material was lower with a PCE value of only $0.7 \%$ instead of $1.7 \%$ observed in the classical P3HT system comparing solar cells with similar layer thickness of approx. $120 \mathrm{~nm}$. The reason was found in the much lower hole mobility in the P3HT-E phase. Smaller domains in the polymer are complicating the charge transport paths and reducing the crystallinity of the polymer phase, both factors decreasing the hole mobility. In thinner devices of approx. $50 \mathrm{~nm}$, in which the negative effect of charge carrier mobility is less important, the P3HT-E/ZnO device (PCE: $0.83 \%$ ) outperformed the P3HT/ZnO (PCE: $0.22 \%$ ) because of its higher charge generation.

In a follow-up paper, P3HT was substituted by P3HS - poly(3hexylselenophene), the selenium containing analogue exhibiting a lower band gap than P3HT [75]. Despite the hopes of the authors, that the combination of $\mathrm{P} 3 \mathrm{HS} / \mathrm{ZnO}$ improves the light harvesting, the prepared solar cells showed lower performance of only $0.4 \%$ PCE under AM1.5G illumination.

As already pointed out by Ref. [73] the conditions during the deposition of the active layer using diethylzinc as precursor determine not only the film thickness but also the phase separation. Han et al. investigated the influence on the relative humidity (values between 3 and 40\%) on a diethylzinc/P3HT system during the spin coating process [76]. Photoluminescence data on the blends showed that the green emission of the $\mathrm{ZnO}$ - attributed by the authors to surface defect states of the nanocrystals acting as radiative trap sites for electrons - is lower in blends obtained at higher humidity. The authors concluded that in these blends the surface area of $\mathrm{ZnO}$ is reduced resulting in less defect states and higher photovoltaic activity. This would also implicate that the humidity has an influence on the morphology (i.e. particle size, agglomeration), however, this was not investigated.

Besides the diethylzinc route, alternative approaches have been introduced. Scientists at the Nanchang University prepared several copolymers consisting of a polythiophene-chain serving as the absorber and donor material and poly(zinc methacrylate) chains [77-79]. The authors prepared block copolymers as well as graft co-polymers. The structures are depicted in Scheme 4. These polymers were coated from chlorobenzene solutions. The resulting precursor film of the active layers contains the zinc source coordinated directly to the polymer phase. This leads to an overall homogeneous distribution of zinc in the bulk, but already with a somehow predefined phase separation caused by the selfassembling properties of such polymers. In a following step the $\mathrm{ZnO}$ phase is formed via hydrolysis by immersing the precursor film in a $1 \mathrm{~mol} / \mathrm{L} \mathrm{NaOH}$ aqueous solution at $60^{\circ} \mathrm{C}$. In the case where the authors used zinc dimethacrylate, already crosslinked polymeric structures were obtained during polymerization $[77,78]$, whereas non crosslinked polymer chains were obtained by using the asymmetric zinc acetate methacrylate as monomer [79].

This approach has the attractiveness that the phase separation can be tuned by the polymer design, however, the work load to synthesize and purify such polymers is rather high. By the use of zinc dimethacrylate a partial crosslinking already of the parent polymer is observed, which might reduce solubility, whereas the residual double bonds can be crosslinked afterwards which could in principle enhance the stability [78]. In addition, the hydrolysis process using sodium hydroxide solution in the device fabrication process might be not compatible with all underlying electrode and interfacial layers. Nevertheless, promising PCEs of $0.6 \%$ have already been obtained with this approach.

In all above described routes to $\mathrm{ZnO} /$ polymer hybrid materials, the formation of the $\mathrm{ZnO}$ phase takes place in the layer by hydrolysis and condensation reactions. Alternatively, these reactions can be carried out in a solution in situ approach before the active layer is coated. The conjugated polymer thereby controls the growth and prevents the crystals from agglomeration and precipitation. Thus, functional groups in the polymer capable to interact with the $\mathrm{ZnO}$ are favourable for this concept.

In this spirit, the growth of $\mathrm{ZnO}$ nanoparticles was controlled by poly(3-alkylthiophene)s, e.g. poly(3-[(2'-(2-ethoxy)ethoxy) ethoxy]-thiophene) P3EEET [80]. The alkoxy-side chains can coordinate to the used zinc cations, which control the growth and interact also with the final $\mathrm{ZnO}$ nanoparticles. Luminescent materials have been obtained but working solar cells have not been presented.

The growth of $\mathrm{ZnO}$ nanoparticles starting from zinc acetate in a mixture of polyvinylalcohol (PVA) and a

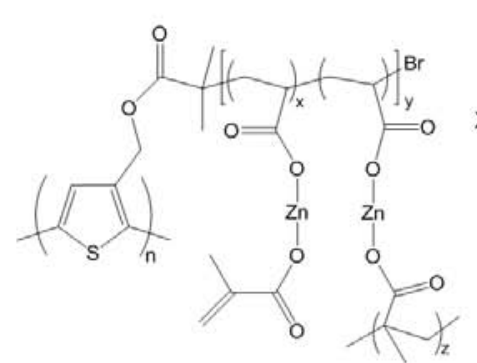

PTh-g-PZMA

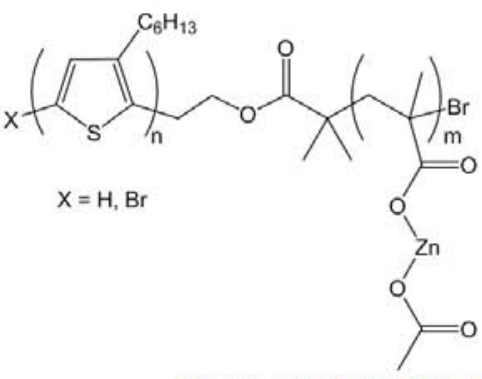

P3HT-b-p[Zn(MAA)(OAc)]

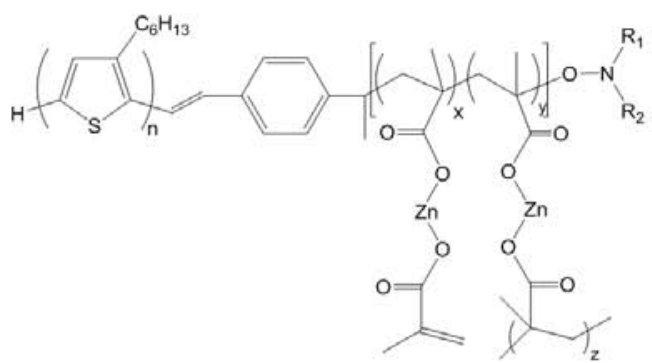

P3HT-b-p $\left[\mathrm{Zn}(\mathrm{MAA})_{2}\right]$

Scheme 4. Structure of P3HT - Zn-methacrylate copolymers: PTh-g-PZMA [77], P3HT-b-p[Zn(MAA)OAc)] [79], P3HT-b-p[Zn(MAA) $)_{2}[78]$. 
poly(paraphenylenevinylene) (PPV)-precursor polymer has been studied by Wang et al. [81]. By controlled hydrolysis/ condensation zinc hydroxide is formed in solution, then the precursor solution is casted onto a PEDOT:PSS layer and during annealing at $160^{\circ} \mathrm{C}$ for $6 \mathrm{~h}$, the zinc hydroxide is converted to $\mathrm{ZnO}$ and at the same time the PPV-precursor to PPV. Solar cells prepared with this method show a PCE of $0.026 \%$. Major issues for these low PCEs could be the remaining PVA polymer - which is a non-conjugated polymer - or that the nanoparticles are not connected to form continuous pathways as indicated by the TEM images.

\subsection{In situ approaches to metal sulfide/selenide/ telluride - conjugated polymer hybrid materials}

Compared to $\mathrm{ZnO}$ and $\mathrm{TiO}_{2}$, many metal sulfides, selenides and tellurides have the advantage of a better suited bandgap for photovoltaic applications. While the most often used metal oxide semiconductors are wide band gap materials $\left(\mathrm{TiO}_{2}: 3.2\right.$ $\mathrm{eV}$ [82], and $\mathrm{ZnO}: 3.4 \mathrm{eV}$ [83]), metal sulfides and selenides have band gaps below $3 \mathrm{eV}$ where higher theoretical efficiencies according to the Schockley-Queisser limit [84] are possible (e.g. CdS: $2.4 \mathrm{eV}$ [85], CdSe: $1.7 \mathrm{eV}$ [86], CulnS $21.5 \mathrm{eV}$ [87], PbS: $0.4 \mathrm{eV}[86])$. However, in the case of metal sulfides and selenides, instead of hydrolysis/condensation reactions induced by water, other reaction paths have to be followed and sulfur, selenium or tellurium has to be supplied by co-reactants or is present as molecular part in a "single source precursor".

\subsubsection{Solution in situ syntheses}

First reports on the synthesis of semiconducting metal sulfide nanoparticles in a solution containing a conjugated polymer stem from Watt et al. published in the years 2004 and 2005 [49,88,89]. Watt et al. describe the in situ preparation of $\mathrm{PbS}$ nanoparticles in the presence of a conjugated polymer, either MEH-PPV or P3HT [90], by heating a solution of $\mathrm{PbAc}_{2}$, elemental sulfur and the polymer in a solvent mixture of DMSO and toluene to $160^{\circ} \mathrm{C}$ for 15 min. Removing excess lead and sulfur ions by precipitation and re-dissolution followed by coating on substrates completes the preparation of the nanocomposite layers. TEM images show that the crystalline nanoparticles are non-aggregated and well dispersed in the polymer matrix (see Figure $6 \mathrm{~A}$ ). The high resolution TEM image of a single nanoparticle (Figure 6B) indicates the high crystallinity of the in situ prepared $\mathrm{PbS}$ nanoparticles.

Hybrid MEH-PPV/PbS solar cells comprising an active layer prepared following this solution in situ approach were presented by Watt et al. [91]. The solar cells with a device architecture of glass/ITO/PEDOT:PSS/MEH-PPV:PbS/AI (ITO: indium tin oxide) exhibited a $\mathrm{V}_{\mathrm{OC}}$ of $1 \mathrm{~V}$, an $\mathrm{I}_{\mathrm{SC}}$ of $0.13 \mathrm{~mA} / \mathrm{cm}^{2}$ and a fill factor (FF) of 0.28 , which leads to a PCE of $0.7 \%$ under $5 \mathrm{~mW} / \mathrm{cm}^{2}$ illumination. The moderate $\mathrm{I}_{\mathrm{SC}}$ and $\mathrm{FF}$ were ascribed to a high series resistance. A possible reason could lie in the separation and thus relatively large particle-particle distance of the $\mathrm{PbS}$ nanoparticles (see Figure 6).

Additionally, the charge carrier transport in the MEH-PPV/ $\mathrm{PbS}$ nanocomposites was investigated using time of flight and steady state current-voltage techniques [92]. It was found out that in the composite the electron and hole mobilities are more balanced and increased compared to a pure MEH-PPV layer as the PbS nanoparticles contribute to an increased electron mobility in the nanocomposite.

An advantage of this solution in situ synthesis route is that size and shape of the nanoparticles can be tuned quite easily. The nanoparticle size can be primarily controlled by variation of the reaction time and temperature. This is particularly interesting as altering the nanoparticle size leads to a shift in their absorption spectrum due to quantum confinement effects, and thus, also the absorption properties of the hybrid solar cells can be tuned without changing the material combination. A controlled formation of nanosized $\mathrm{PbS}$ particles in the presence of the conjugated polymer was shown and attributed to steric effects of the long polymer chains. A dependence of the nanoparticle size on the molecular mass of the polymer was observed: a higher molecular mass of the conjugated polymer led to smaller nanoparticles [88]. Without the polymer, 'bulk' PbS was formed in the reaction solution. Though, as the molecular mass has a
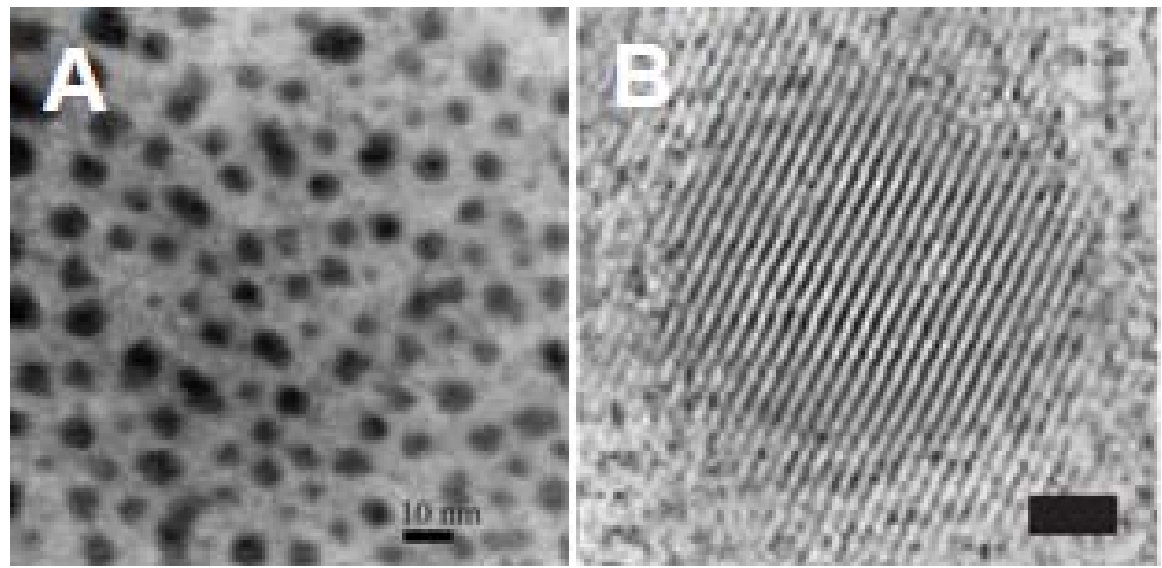

Figure 6. A: dark field scanning TEM image of PbS nanocrystals prepared in a MEH-PPV matrix; B: high resolution dark field TEM image of the lattice planes in a single nanocrystal (bar $=1 \mathrm{~nm}$ ). Reprinted with permission from [91]. Copyright (2005) IOP Publishing Ltd. 
strong influence on the viscosity of the polymer solution and therefore on all diffusion processes in solution, this might also be an explanation. Additionally, a passivation of surface states of the nanoparticles by the polymer was postulated.

The shape of the nanoparticles can be controlled on the one hand by the precursor materials and on the other hand by the solvents or solvent mixtures used for the synthesis. For example, by using elemental sulfur for the reaction, spherical nanoparticles are prepared, while using $\mathrm{H}_{2} \mathrm{~S}$ as sulfur source, cubic nanostructures are formed [49].

Furthermore, Stavrinadis et al. [93] showed that nanorodlike structures can be formed in a MEH-PPV matrix by a post-synthetic treatment. A precipitation of spherical $\mathrm{PbS}$ nanoparticles in MEH-PPV solution using alcohols with appropriate polarity like ethanol, propanol or hexanol led to dipole-induced oriented strings of PbS nanoparticles. As the UVVis absorption of the nanocomposite stays the same after the precipitation it is suggested that the nanorod structures consist of chains of nanoparticles rather than single-crystalline nanorods. A precipitation in methanol for example led to nanocubes and also various other superstructures like elongated parallelograms were observed after precipitation and a mild oxidation of the PbS-nanoparticles in the polymer solution [94].

Following the concept explored for the in situ preparation of $\mathrm{PbS}$ nanoparticles in a solution of a conjugated polymer also other metal sulfides and selenides, e.g. CdS or CdSe, are accessible. Liao et al. prepared CdS/P3HT hybrid materials from Cd(acetate) $\left(\mathrm{H}_{2} \mathrm{O}\right)_{2}$ and elemental sulfur following the same approach as described above for $\mathrm{PbS} /$ polymer materials. They showed that the shape of the nanostructures can be adjusted by the choice of the solvent or solvent mixture $[95,96]$. By using different ratios of dichlorobenzene (DCB) and dimethyl sulfoxide (DMSO), nanorods with various aspect ratios were prepared in a $\mathrm{P} 3 \mathrm{HT}$ matrix. More DCB in the solvent mixture led to an increased aspect ratio of the prepared nanorods, see also Figure 7 [95].

Instead of elemental sulfur, $\mathrm{Na}_{2} \mathrm{~S}$ was used by Sonar et al. to prepare CdS nanoparticles with sizes of 5-6 nm in a P3HT matrix [97]. In the same article, also a method for a solution in

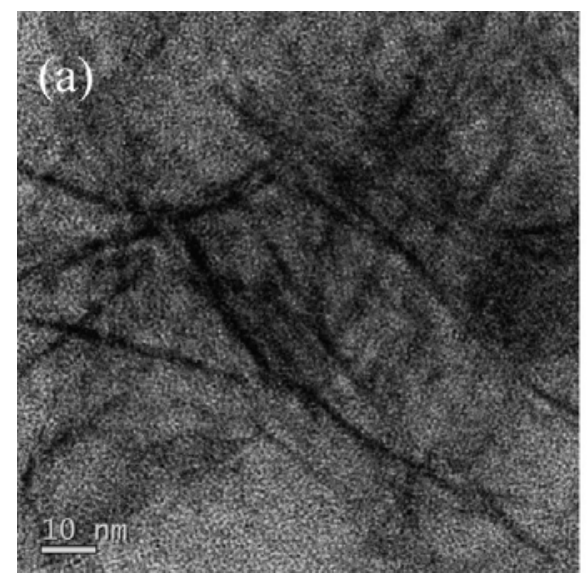

situ synthesis for $\mathrm{CdSe}$ nanoparticles using $\mathrm{Na}_{2} \mathrm{SeO}_{3}$ as selenium source was introduced.

Dayal et al. [98] also prepared CdSe nanoparticles in situ in a P3HT solution in a solvent mixture of trichlorobenzene and 1-octadecene. Dimethylcadmium, which is a quite hazardous reagent, and elemental selenium were used as CdSe-precursors. By heating to $200^{\circ} \mathrm{C}$ or even higher, well dispersed nanoparticles were formed in the P3HT matrix. The prepared nanocomposites were used for the preparation of nanocomposite layers after purification by precipitation and re-dissolution. The P3HT/CdSe nanocomposite layers exhibit photoinduced charge separation between the nanoparticles and $\mathrm{P} 3 \mathrm{HT}$, which confirms that this material is well suited for applications in hybrid solar cells.

However, to our knowledge, no data on P3HT/CdSe hybrid solar cells prepared via the described in situ routes have been published so far, even though the material combination would be prospective, as already a PCE of $2.6 \%$ has been shown with solar cells prepared via the classical route using CdSe nanorods and $\mathrm{P} 3 \mathrm{HT}[99,100]$.

The situation is different in P3HT/CdS hybrid materials. The positive effect of the in situ prepared nanorods concerning photovoltaic applications was elaborated in detail by Liao et al. [95,96]. Hybrid P3HT/CdS layers containing nanorods with higher aspect ratio exhibit more efficient photoluminescence quenching as well as higher solar cell efficiencies compared to devices using spherical nanoparticles [95]. This can be attributed to an increased interaction strength of the nanostructures to the sulfur atoms in $\mathrm{P} 3 \mathrm{HT}$ with increasing aspect ratio, as analysed by ${ }^{1} \mathrm{H}-\mathrm{NMR}$ spectroscopy [96]. Solar cells prepared with nanorods having an aspect ratio of 16 showed the best PCEs exhibiting values up to $2.95 \%$, which are currently the highest reported values for hybrid solar cells prepared via in situ routes [96]. The devices were annealed for $60 \mathrm{~min}$ at $160^{\circ} \mathrm{C}$ to improve the crystallinity of the $\mathrm{P} 3 \mathrm{HT}$ chains. As the longer nanorods facilitate percolation, and thus, electron transport, which is changed from a hopping dominated mechanism in nanoparticles to band conduction dominated transport in nanorods [10], $I_{s c}$ as well as FF are higher with increasing aspect ratio.

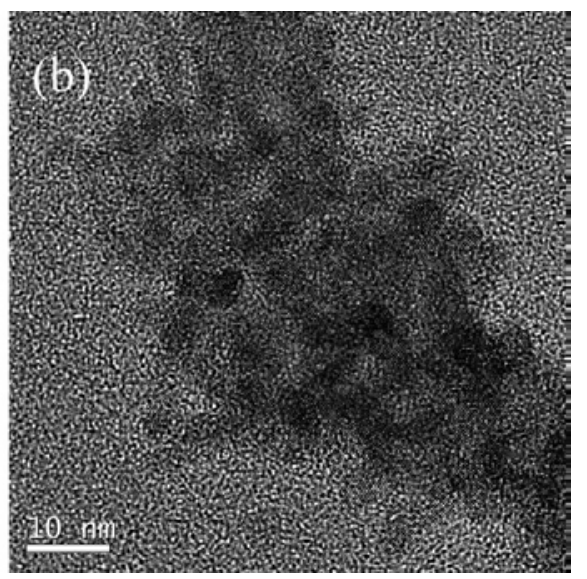

Figure 7. TEM image of CdS nanorods synthesized in P3HT with volume ratios DCB-to-DMSO of (a) 9:3 and (b) 7:5. Reprinted with permission from [95]. Copyright (2010) American Chemical Society. 
Another interesting approach uses unimolecular ('single source') precursors containing already the metal as well as the sulfur source for the formation of metal sulfides. These precursors definitely have the advantage that the sulfur is already covalently linked to the metal atom. Cadmium dodecanthiolate and cadmium benzylthiolate, see also Scheme 1, were introduced as suitable precursors for the synthesis of CdS nanoparticles in polystyrene (PS) [101,102] and poly(methyl methacrylate) (PMMA) [103] matrix. As discussed before, also using these unimolecular precursors, the size of the nanoparticles can be controlled by the temperature as well as by the reaction time. By variation of these two parameters, nanoparticles between 1.0 and $4.6 \mathrm{~nm}$ were prepared in a PS matrix [102]. At a reaction temperature of $300^{\circ} \mathrm{C}$ the nanoparticles grew much faster than at $240^{\circ} \mathrm{C}$.

A similar approach was followed to prepare $\mathrm{P} 3 \mathrm{HT} / \mathrm{CdS}$ nanocomposite layers by using cadmium dodecanethiolate as precursor for photoluminescence studies [104] and the preparation of hybrid solar cells [105]. The prepared glass/ITO/ $\mathrm{P} 3 \mathrm{HT}$ :CdS/Al solar cells exhibit very low EQE, which is ascribed to the relatively high decomposition temperature of cadmium dodecanethiolate. Unreacted precursors lower the conductivity in the film and remaining dodecanethiol groups attached to the nanoparticle surface may hinder charge separation. Changing the linear alkyl side chain to benzylic side chains and introducing methyl imidazole as co-ligand reduces the decomposition temperature of the thiolate precursor to $175^{\circ} \mathrm{C}$, which is about $100^{\circ} \mathrm{C}$ lower than for the linear alkyl thiolate [106]. However, up to now, no results on hybrid solar cells prepared using the optimized thiolate-precursors with lower decomposition temperature have been reported.

Recently, a not defined cadmium ethyl xanthate complex was used as precursor for the preparation of a $\mathrm{P} 3 \mathrm{HT} / \mathrm{CdS}$ nanocomposite [107]. The photoluminescence of P3HT in the nanocomposite is partly quenched compared to pure $\mathrm{P} 3 \mathrm{HT}$ implying charge transfer from $\mathrm{P} 3 \mathrm{HT}$ to $\mathrm{CdS}$. However, no results on solar cells have been reported, so far.

Overall, despite a relatively high number of publications deals with the solution in situ fabrication of nanocomposites containing metal sulfide nanoparticles and a conjugated polymer and the versatility of this approach to prepare nanoparticles with different sizes and shapes was demonstrated, only very few works focused on solar cell fabrication using this in situ approach. Nevertheless, PCEs exhibiting values up to $2.95 \%$ have already been reached [96], which shows the potential of this approach.

Some works are focusing on the combination of polymer/ [6,6]-Phenyl $\mathrm{C}_{61}$ butyric acid methyl ester (PCBM) solar cells with in situ prepared semiconducting nanoparticles. Here, the nanoparticles may act only as sensitizers, contributing to increased light-harvesting and thereby to higher charge generation, but not necessarily to charge transport, which is in contrast to classical hybrid solar cells where the nanoparticles are also responsible for charge transport [108].

The influence of in situ prepared CdTe nanoparticles in a P3HT solution on P3HT/PCBM solar cells was studied by Khan et al. [109]. The CdTe nanoparticles were synthesized from cadmium acetate dihydrate and a tellurium precursor prepared from elemental tellurium and trioctylphosphine in a $\mathrm{P} 3 \mathrm{HT}$ solution in chlorobenzene. In the prepared P3HT/CdTe/PCBM solar cells an increase of $\mathrm{I}_{\mathrm{SC}}$ and $\mathrm{V}_{\mathrm{OC}}$ was observed compared to P3HT/PCBM solar cells, however, the FF decreased. Thus, the overall PCE increased slightly from $0.72 \%$ to $0.79 \%$ for the ternary system.

Kwak et al. [110] prepared PbS nanoparticles in a P3HT solution by reacting lead chloride and sulfur in a solvent mixture of dichlorobenzene and DMSO at $180^{\circ} \mathrm{C}$. The size of the nanoparticles was $15-25 \mathrm{~nm}$. After adding PCBM to the $\mathrm{P} 3 \mathrm{HT} / \mathrm{PbS}$ solution, solar cells were prepared and an increase of efficiency compared to the reference P3HT/PCBM device was observed.

However, in these studies pure polymer/PCBM reference systems with relatively low efficiencies, compared to standard values of this solar cell technology [1], are used. If nanoparticle sensitizers also further enhance the efficiency of a polymer/ PCBM solar cell with, for example, an efficiency higher $6 \%$, or not, is still an open issue to be clarified.

\subsubsection{Solid state in situ syntheses}

Alternatively to the preparation of the nanoparticles in a solution containing the conjugated polymer, the reaction to the metal sulfides can be carried out without solvent via a mild thermal treatment of precursors, which react to the metal sulfides, directly in the polymer matrix in the solid state.

In a first report CulnS ${ }_{2}$ nanoparticles were prepared in a polymer matrix by using Cul and $\mathrm{InCl}_{3}$ as well as thioacetamide as precursors for the nanoparticles [111]. Due to the limited solubility of these precursors, a solvent mixture of water, ethanol and pyridine was used in which also the precursor for PPV, poly(p-xylene tetrahydrothiophenium)chloride, is soluble. After coating the solution on the substrate and slow evaporation of the solvents, the layer is heated to $200^{\circ} \mathrm{C}$. During this heating step, thioacetamide decomposes and releases reactive sulfur-species which react with the metal ions present in the layer to form CulnS $_{2}$ nanoparticles in the PPV matrix. The conjugated polymer PPV is also formed during the annealing step by cleavage of $\mathrm{HCl}$ and tetrahydrothiophene from the PPV precursor material. By this method hybrid solar cells with an efficiency of $0.75 \%$ could be obtained and the incident photon-to-current conversion efficiency (IPCE) spectrum showed that both the organic and the inorganic component contribute to charge generation in the active layer. Despite this promising efficiency, further optimization of this system was challenging due to the limited solubility of the precursors. Additionally, the poor stability of PPV based materials, known from literature [112], directed the research towards more stable conjugated polymers.

Thus, in subsequent studies, nanocomposite layers containing CdS, ZnS [113], and CulnS 2 [114] nanoparticles have been realized starting from the corresponding metal salts and thiourea. As conjugated polymer poly(3-(ethyl-4-butanoate)thiophene) (P3EBT) was selected due to its solubility in pyridine which is enabled by its 
polar side chains. The pyridine solutions allowed a more convenient coating and precursor layers with better homogeneity have been obtained. The conversion to the hybrid materials was realized at temperatures of $180^{\circ} \mathrm{C}$ under reduced pressure. However, the PCEs remained low: P3EBT/CdS solar cells exhibited PCEs of about $0.06 \%$ and P3EBT/CulnS ${ }_{2}$ solar cells PCEs of $0.4 \%$. We ascribe these moderate efficiencies to the formation of the non-volatile by-product melamine originating from the trimerization reaction of thiourea [114]. In addition, theoretical considerations indicated that the insignificant energy level offset between the HOMO of P3EBT and the valence band of CulnS ${ }_{2}$, also limits the theoretical PCEs of this material combination $[115,116]$.

Nevertheless, the stability of the prepared CulnS $_{2} /$ P3EBT hybrid solar cells were improved compared to CulnS $_{2} / P P V$ hybrid devices.

In the last years, metal xanthate precursors have been developed for the solid state in situ synthesis of hybrid materials, outpacing the problems of solubility and side products. Via this metal xanthate route polymer/CdS and polymer/CulnS $S_{2}$ hybrid solar cells have been prepared so far $[35,117,118]$. In both routes metal xanthate derivatives, soluble in apolar organic solvents, are used as precursors. Figure 8 illustrates this new in situ approach. Metal xanthates are dissolved together with a conjugated polymer in an apolar organic solvent. The advantages of metal xanthates are that they decompose at temperatures significantly below $200^{\circ} \mathrm{C}$ and that their solubility can be tuned by varying the alkyl moiety of the xanthate group. Additionally, co-ligands like pyridine can be introduced to optimize decomposition temperature and solubility. Despite their relatively low decomposition temperatures, they are stable over a long time at room temperature, even in solution.
For the preparation of the nanocomposite layer, the solution containing metal xanthates and conjugated polymer is coated onto a substrate and the dried layer is subjected to a mild thermal annealing step at temperatures of about $160-200^{\circ} \mathrm{C}$, which is compatible with many conjugated polymers, with roll-to-roll fabrication processes, and with the use of flexible substrates [119]. During this annealing step, the metal xanthates decompose and the metal sulfide nanoparticles are formed in the polymer matrix. All the by-products of the decomposition reaction (COS, $\mathrm{CS}_{2}$, and the corresponding alkene and alcohol), which proceeds related to the Chugaev reaction [120] are volatile and evolve from the layer, so that no remaining side-products could be detected in the active layer [35].

A first report on hybrid solar cells prepared in situ using metal xanthate precursors was published in 2010 by the group of Haque [117]. Cadmium ethyl xanthate (Cd(ethylxanthate) $\left.)_{2}(\text { pyridine })_{2}\right)$, see also Scheme $1 \mathrm{C}$, was chosen as CdS precursor in this study, as this compound is more soluble as the uncomplexed analogue. The decomposition of the $\mathrm{Cd}$-xanthate starts at $50^{\circ} \mathrm{C}$ and is completed at $150^{\circ} \mathrm{C}$. After this annealing, an interpenetrating $\mathrm{P} 3 \mathrm{HT} / \mathrm{CdS}$ network is formed and the nanocomposite layers show high yield of photogenerated long-lived charges. The prepared $\mathrm{P} 3 \mathrm{HT} / \mathrm{CdS}$ solar cells exhibited efficiencies of $0.7 \%$. By optimization of the annealing temperature, which influences the nanomorphology of the P3HT/CdS layers, and the device architecture, the PCE of the hybrid solar cells was increased to $2.2 \%$ [118]. A comparison of this approach with the classical approach [31] was already discussed in section 2.1.

Using copper and indium O-2,2-dimethylpentan-3-yl xanthate (see Scheme 1D), hybrid solar cells having absorber layers, consisting of in situ prepared copper indium sulfide
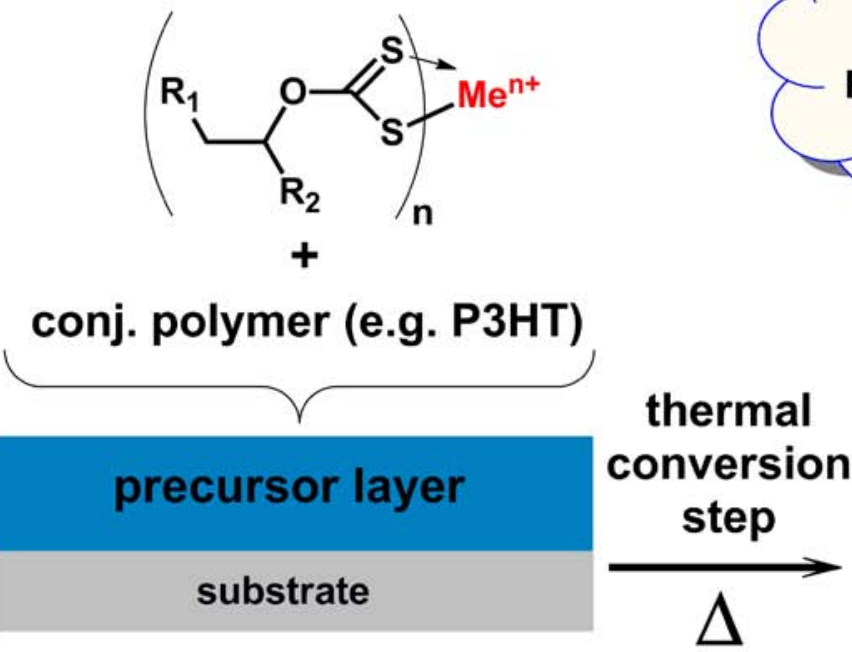

precursor layer
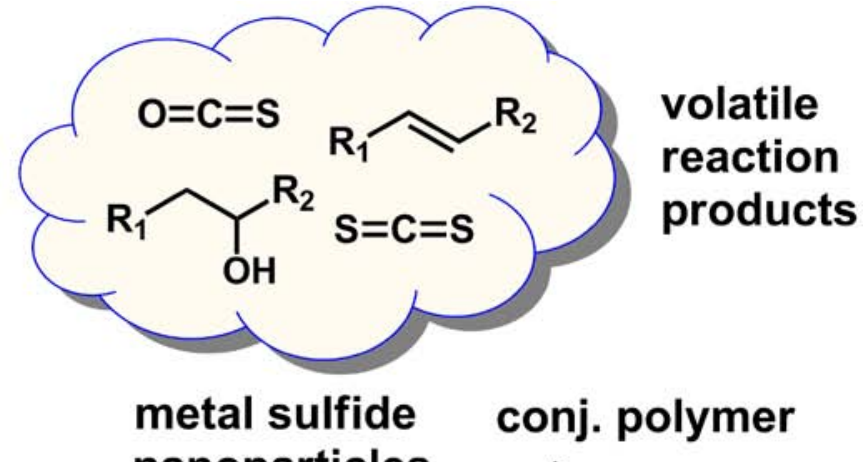
nanoparticles

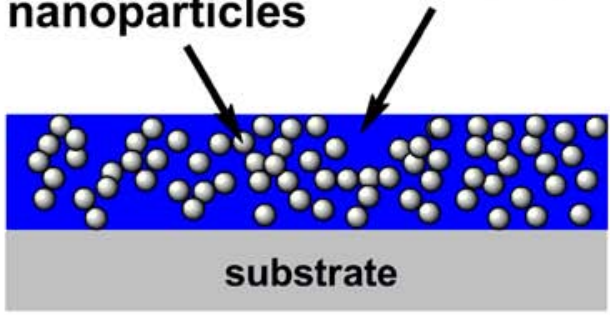

polymer / metal sulfide nanocomposite

Figure 8. Scheme of the metal xanthate - solid state in situ route (Me: metal ions, $\mathrm{Cu}, \mathrm{In}, \mathrm{Cd} ; \mathrm{n=0xidation}$ number of the metal; $R_{1}, R_{2}: H$, alkyl). 
nanoparticles and the low band gap polymer (poly[(2,7silafluorene)-alt-(4,7-di-2-thienyl-2,1,3-benzothiadiazole)]) PSiFDBT exhibited PCEs of $2.8 \%$, so far [35]. The IV-curves of a typical PSiF-DBT/CulnS ${ }_{2}$ (CIS) solar cell are depicted in Figure $9 \mathrm{~A}$. The solar cell exhibits a quite high $\mathrm{I}_{\mathrm{sc}}$ of $10.3 \mathrm{~mA} / \mathrm{cm}^{2}$ and a $\mathrm{V}_{\mathrm{OC}}$ of $540 \mathrm{mV}$. With a FF of $50 \%$ an efficiency of $2.8 \%$ is obtained under $100 \mathrm{~mW} / \mathrm{cm}^{2}$ AM1.5 illumination. The device architecture (glass/ITO/PEDOT:PSS/PSiF-DBT:CIS/Al) is shown in Figure $9 \mathrm{~B}$. The bright field TEM image of a cross section of the solar cell (Figure $9 \mathrm{C}$ ) shows that in the active layer (4) nanoparticles with sizes of 3-5 $\mathrm{nm}$ form a dense network in the PSiF-DBT matrix. The generated copper indium sulfide nanoparticles are indiumrich, a Cu:In ratio of 1:1.6 was found.

By modification of the Al-electrode of the PSiF-DBT/CIS hybrid solar cells it was possible to improve the FF to $56 \%$ [121]. Before the deposition of the Al-electrode, a very thin layer of $\mathrm{Ag}$ was deposited on the nanocomposite layer, which led to $\mathrm{Ag}$ nanoparticles in the aluminium oxide layer, which forms at the interface to the nanocomposite layer. Using these $\mathrm{Ag} / \mathrm{Al}$ electrodes, the series resistance of the devices is significantly lowered, which can be ascribed to the Ag nanoparticles, which facilitate charge transport through the aluminium oxide layer. In addition, it was also successfully shown that solution-processed small molecule/CIS hybrid solar cells can be prepared via the xanthate route [122].

This xanthate in situ approach is very prospective keeping in mind that this is a rather young research topic. Further optimization of the device architecture, as well as for example, introducing tailored interface layers, could lead to a further improvement of in situ prepared hybrid solar cells.

Another possibility would be to work on the controlled variation of nanoparticle size by modification of the precursors, as it was successfully shown for the in situ metal sulfide formation in solution, where it was demonstrated that the nanoparticle sizes vary by using different precursors. In smaller nanoparticles, the number of surface atoms is higher compared to bulk atoms, which, overall, leads to more surface defects due to dangling bonds in the nanocomposite layer. By using bigger nanoparticles the density of such surface defects would be intrinsically reduced, which should lead to an improved device performance [123]. Remaining dangling bonds could be further reduced by the introduction of small molecules like pyridine or butanethiol [124].

On the other hand, the strategy to prepare nanorods by changing the intermolecular distance between the polymer chains by using solvent mixtures cannot be implement directly to this solid state approach due to the lack of a solvent as influencing factor. However, maybe such structures could be achieved also in a solid state reaction by pre-templating of the polymer matrix by self-assembly during the coating and drying step of the precursor solution.

A disadvantage of this solid state in situ approach is that metal selenides are not accessible with the currently known precursors. Selenourea would be a possibility, however, expected side product formation [114], challenging solubility and toxicity are arguments lowering the attractiveness of this precursor.
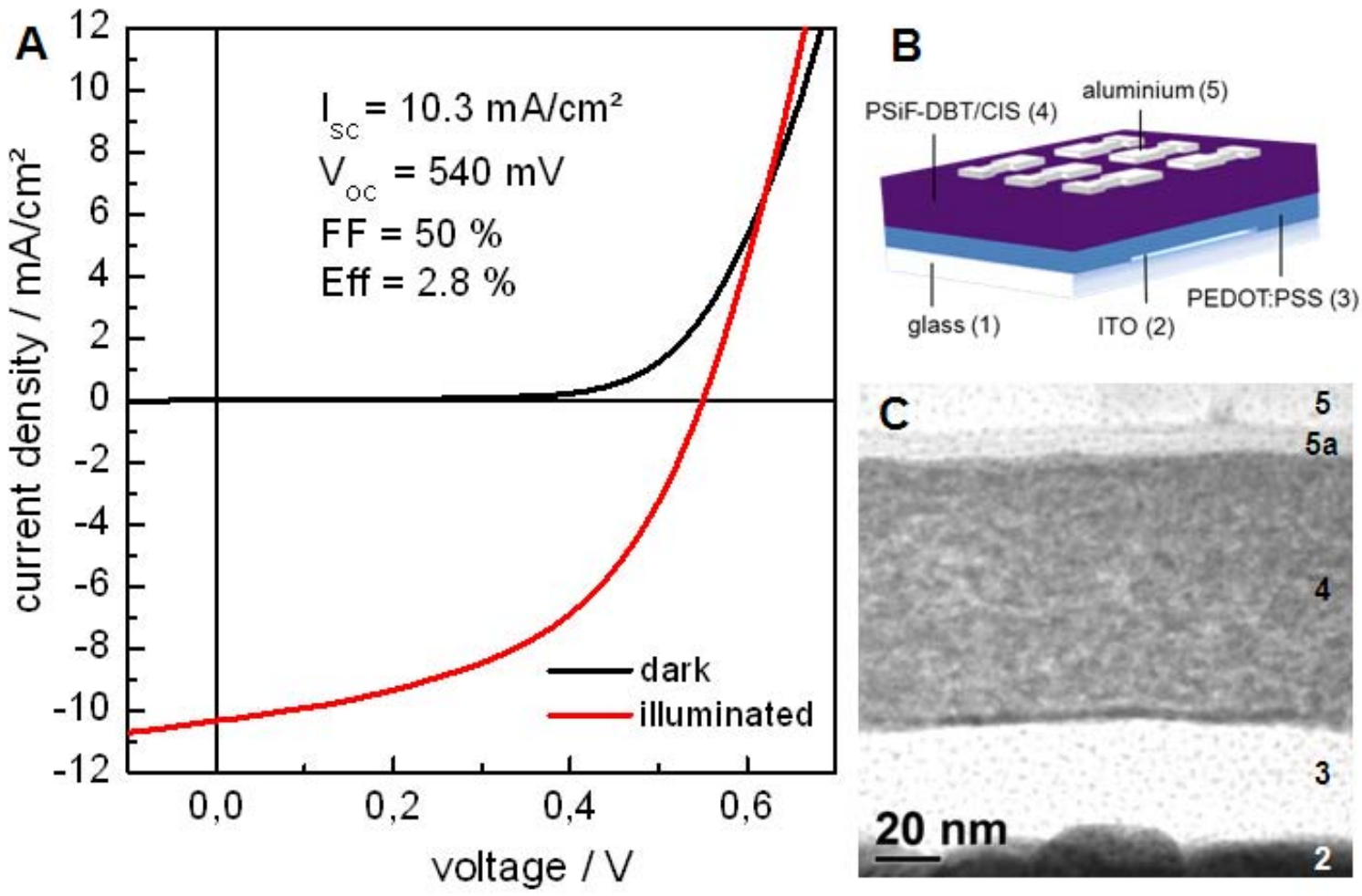

Figure 9. A: Current-voltage (I-V) characteristics of a typical PSiF-DBT/CIS nanocomposite solar cell with Al-electrodes; B: solar cell architecture; C: BF-TEM of a cross-section (FIB-lamella) of the solar cell, 1: glass; 2: ITO; 3: PEDOT:PSS; 4: nanocomposite layer; 5a: aluminium oxide; 5: aluminium. Reprinted with permission from [35]. Copyright (2011) Wiley. 


\subsection{Examples of further ligand-free methods for the preparation of nanocomposite layers}

There are also other routes, belonging mainly to the infiltration approach, which are often denoted as "in situ" routes.

The infiltration method for the preparation of organic/ inorganic hybrid layers is well-known for metal oxide/polymer composites [24,55], but recently also a related method for the preparation of metal sulfide nanostructures (e.g. nanosheet arrays, nanoflakes) of $\operatorname{In}_{2} \mathrm{~S}_{3}$ [125], $\mathrm{Ag}_{2} \mathrm{~S}$ [126], and $\mathrm{Bi}_{2} \mathrm{~S}_{3}$ [127] was introduced. The nanostructures are prepared during the device assembly on the electrode and after infiltration with a conjugated polymer the hybrid solar cells are finished with the deposition of metal electrodes. The best PCEs (2.04\%) following this route were achieved using $\mathrm{Ag}_{2} \mathrm{~S}$ in combination with $\mathrm{P} 3 \mathrm{HT}$. The $\mathrm{Ag}_{2} \mathrm{~S}$ nanosheet arrays on the ITO substrate were formed by treatment of an elemental silver layer on the ITO substrate with elemental sulfur in DMF at $25^{\circ} \mathrm{C}$ for $8 \mathrm{~h}$. Afterwards, the metal sulfide structure was infiltrated and covered with $\mathrm{P} 3 \mathrm{HT}$ from a chlorobenzene solution before gold electrodes were deposited on top. The resulting solar cells exhibited an amazingly high $\mathrm{I}_{\mathrm{sc}}$ of $18.2 \mathrm{~mA} / \mathrm{cm}^{2}, \mathrm{a} \mathrm{V}_{\mathrm{OC}}$ of $0.27 \mathrm{~V}$ and an efficiency of $2.04 \%$ [126]. The same group also prepared $\mathrm{P} 3 \mathrm{HT} / \mathrm{In}_{2} \mathrm{~S}_{3}$ hybrid solar cells via a quite similar route. Differences lay in the treatment of the elemental indium layer, where ethanol was used as solvent and the reaction to $\ln _{2} S_{3}$ had to be carried out in a sealed autoclave at $180^{\circ} \mathrm{C}$, as well as in the solar cell assembly, where a PEDOT:PSS layer and aluminum instead of gold electrodes were used. Anyway, in this case PCEs of only $0.04 \%$ were obtained [125]. $\mathrm{P} 3 \mathrm{HT} / \mathrm{Bi}_{2} \mathrm{~S}_{3}$ hybrid solar cells, which were also prepared according to the described procedure, exhibited very low $\mathrm{V}_{\mathrm{OC}}$, which led to an efficiency of $0.005 \%$ [127]. However, the material combination $\mathrm{P} 3 \mathrm{HT} / \mathrm{Ag}_{2} \mathrm{~S}$ highlights the potential of this approach and enhancement of the efficiencies can be expected by further optimization in the near future.

As infiltration of polymers into nanopores is often challenging, the conjugated polymer can be polymerized in situ in the nanostructures. Prominent examples are the in situ polymerizations of $\mathrm{P} 3 \mathrm{HT}$ or $\mathrm{MEH}-\mathrm{PPV}$ in or on $\mathrm{TiO}_{2}$ nanostructures [128-131].

A further approach to prepare metal sulfide nanoparticles in a polymer matrix was reported by Mejía et al. [132]. They introduced a seeded growth of CdS nanoparticles within an electropolymerized conducting metallopolymer matrix. The metal atoms in the metallopolymer consisting of N,N'-((2,2'dimethyl)propyl)bis(5-(2,2'bithiophene-5-yl)salcylideniminato cadmium(II) monomers act as seed points for the defined growth of the approx. $5 \mathrm{~nm}$ big CdS nanoparticles in the polymer matrix. The CdS growth is realized by repeated treatment of the electropolymerized thin films with a saturated solution of $\mathrm{H}_{2} \mathrm{~S}$ in $\mathrm{CH}_{2} \mathrm{Cl}_{2}$ followed by a solution containing $\mathrm{Cd}\left(\mathrm{NO}_{3}\right)_{2}$.

An alternative "inverse" in situ concept describes the preparation of functionalized nanoparticle sols with polymerizable ligands e.g. for $\mathrm{TiO}_{2} /$ polypyrrole or $\mathrm{TiO}_{2} /$ polyaniline hybrid materials. In this route the polymers are formed in the presence of $\mathrm{TiO}_{2}$ nanoparticles. After the preparation of the
$\mathrm{TiO}_{2}$ nanoparticles capped with polymerizable pyrrole ligands, these precursors were coated on a substrate and the pyrrole ligands were polymerized in the layer [133]. In the case of $\mathrm{TiO}_{2} /$ polyaniline, the functionalized nanoparticles were copolymerized with aniline in solution using emulsion polymerization protocol giving the final hybrid materials [134]. Similar approaches have also been developed for e.g. CdSe/PPV [135] or CdSe/ oligofluorene [136] nanocomposites, in both nanoparticles were capped with polymerizable ligands.

These few, not comprehensive, examples demonstrate that there are many interesting possibilities to fabricate inorganicorganic hybrid materials following other innovative synthesis approaches besides in situ formation of nanoparticles in the polymer matrix which is the subject of this review.

\section{Conclusions and Outlook}

Table 1 summarizes important examples of inorganic-organic hybrid solar cells prepared by in situ routes. The record PCEs of in situ prepared hybrid solar cells are approaching 3\% and are thereby about only $1 \%$ behind the efficiencies of hybrid solar cells prepared via the classical approach, which exhibit currently a maximum PCE of $4.1 \%$ for P3HT/CdS hybrid solar cells [5]. Looking at in situ prepared solar cells, this material combination is also in the lead. PCEs of $2.9-2.95 \%$ have been obtained for solar cells containing solution in situ prepared CdS nanorods in P3HT matrix [95,96]. Efficiencies which are closely behind are already reported for hybrid solar cells prepared by the metal xanthate route, a solid state in situ approach. For Culns $\mathrm{S}_{2} / \mathrm{PSiF}-\mathrm{DBT}$ solar cells, efficiencies of $2.8 \%$ were demonstrated [35], whereas for CdS/P3HT, PCEs of $2.17 \%$ have been shown [118]. Only for one metal oxide/polymer material combination, $\mathrm{ZnO} / \mathrm{P} 3 \mathrm{HT}$, solar cells with efficiencies of $2 \%$ could be obtained via the diethylzinc route [30]. In this context, it should be noted that all of these combinations have quite different polymer/nanoparticle volume ratios. The volume fraction of the CdS nanorods in the in situ prepared record solar cells with PCEs of $2.95 \%$ exhibits only a value of $20 \%$ or even lower. Similar low values are reported for the $\mathrm{ZnO} / \mathrm{P} 3 \mathrm{HT}$ combination, whereas in the materials prepared by the xanthate route, the volume fraction of the inorganic phase was much higher, approx. $50 \%$ in CdS/P3HT and $65 \%$ for CulnS $_{2} /$ PSiF-DBT solar cells. Interestingly, in the cases of CdS nanorods and $\mathrm{ZnO}$ nanoparticles, the thickness of the reported solar cells is in the range of approx. $200 \mathrm{~nm}$. High efficiencies can only be reached in such thick layers if the charge carrier mobility in both phases is also sufficiently high. In contrast to this, the layer thicknesses of CulnS $S_{2} / \mathrm{PSiF}-\mathrm{DBT}$ and CdS/P3HT solar cells were only in the range of $80-100 \mathrm{~nm}$, indicating lower charge carrier mobility in, at least, one phase. Thus, it should be emphasized that also in the case of inorganic-organic hybrid solar cells, a thorough optimization is necessary for each new material combination and all parameters regarding light absorption, charge carrier generation, transport, and extraction have to be adjusted. 
Table 1. Important examples of in situ prepared hybrid solar cells.

\begin{tabular}{|c|c|c|c|c|c|c|c|c|c|}
\hline $\begin{array}{c}\text { Inorganic } \\
\text { Phase }\end{array}$ & Organic Phase & Precursor & $\begin{array}{l}\text { Solution/ } \\
\text { Solid State }\end{array}$ & $\mathrm{I}_{\mathrm{sc}} / \mathrm{mA} / \mathrm{cm}^{2}$ & $\mathrm{v}_{\mathrm{oc}} / \mathrm{V}$ & FF / \% & Eff. / \% & Year & Ref. \\
\hline CdS & Р3HT & $\begin{array}{l}\mathrm{CdAc}_{2} \cdot 2 \mathrm{H}_{2} \mathrm{O} \\
\text { Elemental Sulfur }\end{array}$ & Solution & - & - & - & 2.95 & 2011 & [96] \\
\hline CdS & P3HT & $\begin{array}{l}\mathrm{CdAc}_{2} \cdot 2 \mathrm{H}_{2} \mathrm{O} \\
\text { Elemental Sulfur }\end{array}$ & Solution & 9.0 & 0.64 & 48 & 2.9 & 2009 & [95] \\
\hline CulnS $_{2}$ & PSiF-DBT & Xanthates & Solid State & 10.3 & 0.54 & 50 & 2.8 & 2011 & [35] \\
\hline CulnS $_{2}$ & PSiF-DBT & Xanthates & Solid State & 10.4 & 0.46 & 56 & 2.66 & 2012 & [121] \\
\hline CdS & Р3HT & Xanthates & Solid State & 4.85 & 0.84 & 53 & 2.17 & 2011 & [118] \\
\hline $\mathrm{ZnO}$ & Р3HT & Diethylzinc & Solid State & 5.2 & 0.75 & 52 & 2.0 & 2009 & [30] \\
\hline $\mathrm{ZnO}$ & Р3HT & Diethylzinc & Solid State & 3.3 & 0.83 & 50 & 1.4 & 2007 & [72] \\
\hline CulnS $_{2}$ & $\mathrm{p}$-DTS $\left(\mathrm{FBTTh} \mathrm{h}_{2}\right)_{2}^{*}$ & Xanthates & Solid State & 5.5 & 0.46 & 52 & 1.3 & 2013 & [122] \\
\hline $\mathrm{ZnO}$ & Р3HT & Diethylzinc & Solid State & 2.7 & 0.78 & 49 & 1.19 & 2012 & [76] \\
\hline $\mathrm{ZnO}$ & MDMO-PPV & Diethylzinc & Solid State & 2.3 & 1.14 & 42 & 1.1 & 2005 & [70] \\
\hline $\mathrm{TiO}_{2} / \mathrm{SiO}_{2}$ & TPV-Si* & $\mathrm{Ti}(\mathrm{O} \mathrm{Pr})_{4} / \mathrm{Si}(\mathrm{OEt})_{4}$ & Solution & 2.79 & 0.72 & 54 & 1.09 & 2006 & [65] \\
\hline $\mathrm{ZnO}$ & Р3HT-E & Diethylzinc & Solid State & 2.1 & 1.02 & 40 & 0.83 & 2011 & [74] \\
\hline CulnS $_{2}$ & PPV & Cul, InCl ${ }_{3}$, Thioacetamide & Solid State & 2.1 & 0.7 & 30 & 0.75 & 2010 & [111] \\
\hline $\mathrm{PbS}$ & MEH-PPV & $\begin{array}{l}\mathrm{PbAc}_{2} \text {, } \\
\text { Elemental Sulfur }\end{array}$ & Solution & 0.13 & 1 & 28 & 0.7 & 2005 & [91] \\
\hline CdS & P3HT & Xanthates & Solid State & 3.54 & 0.61 & 33 & 0.7 & 2010 & [117] \\
\hline $\mathrm{ZnO}$ & $\mathrm{P} 3 \mathrm{HT}^{\star \star}$ & $p\left(Z n-M A A_{2}\right)$ & Solid State & 2.9 & 0.5 & 43 & 0.62 & 2012 & [78] \\
\hline $\mathrm{ZnO}$ & P3HS & Diethlylzinc & Solid State & 1.8 & 0.6 & 38 & 0.42 & 2011 & [75] \\
\hline CulnS $_{2}$ & P3EBT & CuAc, $\operatorname{lnCl}{ }_{3}$, Thiourea & Solid State & 1.4 & 0.66 & 27 & 0.42 & 2011 & [114] \\
\hline $\mathrm{TiO}_{2}$ & Р3ОТ & $\mathrm{Ti}(\mathrm{OPr})_{4}$ & Solid State & 1 & - & - & 0.22 & 2004 & [56] \\
\hline $\mathrm{TiO}_{2}$ & MDMO-PPV & $\mathrm{Ti}(\mathrm{O} \mathrm{Pr})_{4}$ & Solid State & 0.87 & 0.52 & 42 & 0.19 & 2003 & [29] \\
\hline $\mathrm{ZnO}$ & $\mathrm{P} 3 \mathrm{HT}^{\star \star}$ & $p(\mathrm{Zn}(\mathrm{MAA})(\mathrm{OAc}))$ & Solid State & 1.7 & 0.37 & 31 & 0.19 & 2011 & [79] \\
\hline $\mathrm{TiO}_{2}$ & MDMO-PPV & $\mathrm{Ti}(\mathrm{OPPr})_{4}$ & Solid State & 1 & - & - & 0.17 & 2004 & [56] \\
\hline $\mathrm{TiO}_{2}$ & MDMO-PPV & $\mathrm{Ti}(\mathrm{OPPr})_{4}$ & Solid State & - & - & - & 0.14 & 2005 & [52] \\
\hline $\mathrm{TiO}_{2}$ & Р3HT-OH & $\mathrm{Ti}\left(\mathrm{O}^{n} \mathrm{C}_{4} \mathrm{H}_{9}\right)$ & Solution & 0.67 & 0.43 & 48 & 0.12 & 2008 & [62] \\
\hline CdS & P3EBT & $\mathrm{CdAc}_{2} \cdot 2 \mathrm{H}_{2} \mathrm{O}$, Thiourea & Solid State & 0.46 & 0.51 & 28 & 0.06 & 2011 & [113] \\
\hline $\mathrm{TiO}_{2}$ & P3HT & $\mathrm{Ti}\left(\mathrm{O}^{\mathrm{n}} \mathrm{C}_{4} \mathrm{H}_{9}\right)$ & Solution & 0.20 & 0.55 & 41 & 0.05 & 2008 & [62] \\
\hline $\mathrm{ZnO}$ & PPV & $\mathrm{Zn}(\mathrm{OAc})_{2}$ & $\begin{array}{l}\text { Solution/ } \\
\text { Solid State }\end{array}$ & 0.09 & 0.94 & 30 & 0.026 & 2009 & [81] \\
\hline
\end{tabular}

In this regard, it is remarkable that solar cells with PCEs approaching $3 \%$ have been already realized, even though only approximately 30 publications dealing with in situ prepared nanoparticle/polymer hybrid solar cells with significant PCEs have been reported.

Comparing this situation with the literature on e.g. the one material combination P3HT/PCBM with more than hundred papers dealing with different aspects how morphology, interfacial layers, electrodes, device architecture and many other parameters influence the solar cell properties, it can be assumed that a lot of potential improvements might be disclosed in near future if research on in situ prepared hybrid solar cells is conducted with similar effort.
To bring in situ prepared hybrid solar cells to the next level, the same challenges also experienced in polymer/PCBM solar cells and hybrid solar cells prepared via the classical route have to be tackled. These include issues of morphology, energy level engineering, device architecture, interfacial layers, electrodes and stability. In this context, the morphology in in situ preparation routes can be more easily influenced in solution in situ approaches, whereas it is more difficult to "design" morphologies with solid state in situ routes. In the first case, nanoparticles as well as nanorods of CdSe have already been realized. In general for both in situ approaches, thorough investigations on the formation mechanism and its kinetics for 
each precursor route would help to gain information about how to tune the shape and size of the inorganic nanostructures. For example, it will be especially exciting to follow if it will also be possible to synthesize nanorods in solid state reactions in conjugated polymer matrices.

Moreover, purity is an important aspect in in situ prepared nanocomposite layers, as purification is often not possible. Therefore, the selection of precursor materials and reactions to form the nanoparticles has to be done also concerning yield and by-product formation, whereby close to quantitative yields and volatile by-products, if there are formed any, are essential.

A further issue is the tuning of the interface between the inorganic and organic semiconductor. While in the classical route a lot of effort was spent to optimize the nanoparticle surfaces by various ligands, the surface chemistry of the in

\section{References}

[1] Li G., Zhu R., Yang Y., Polymer solar cells, Nat. Photonics, 2012, 6, 153-161.

[2] Press release - Heliatek, http://www.heliatek.com/ newscenter/latest_news/neuer-weltrekord-fur-organischesolarzellen-heliatek-behauptet-sich-mit-12-zelleffizienz-alstechnologiefuhrer/?lang=en, accessed on Jan 28, 2013.

[3] Green M.A., Emery K., Hishikawa Y., Warta W., Dunlop E.D., Solar cell efficiency tables (version 40), Prog. Photovolt: Res. Appl., 2012, 20, 606-614.

[4] Gevorgyan S.A., Medford A.J., Bundgaard E., Sapkota S.B., Schleiermacher H., Zimmermann B., Würfel U., Chafiq A., Lira-Cantu M., Swonke T., Wagner M., Brabec C.J., Haillant O., Voroshazi E., Aernouts T., Steim R., Hauch J.A., Elschner A., Pannone M., Xiao M., Langzettel A., Laird D., Lloyd M.T., Rath T., Maier E., Trimmel G., Hermenau M., Menke T., Leo K., Rösch R., Seeland M., Hoppe H., Nagle T.J., Burke K.B., Fell C.J., Vak D., Singh T.B., Watkins S.E., Galagan Y., Manor A., Katz E.A., Kim T., Kim K., Sommeling P.M., Verhees W.J.H., Veenstra S.C., Riede M., Christophoro M.G., Currier T., Shrotriya V., Schwartz G., Krebs F.C., An inter-laboratory stability study of roll-to-roll coated flexible polymer solar modules, Sol. Energy Mater. Sol. Cells, 2011, 95, 13981416.

[5] Ren S., Chang L.-Y., Lim S.-K., Zhao J., Smith M., Zhao N., Bulovic V., Bawendi M., Gradecak S., Inorganic-Organic Hybrid Solar Cell: Bridging Quantum Dots to Conjugated Polymer Nanowires, Nano Lett., 2011, 11, 3998-4002.

[6] Seo J., Cho M.J., Lee D., Cartwright A.N., Prasad P.N., Efficient Heterojunction Photovoltaic Cell Utilizing Nanocomposites of Lead Sulfide Nanocrystals and a LowBandgap Polymer, Adv. Mater., 2011, 23, 3984-3988.

[7] Zhou R., Zheng Y., Qian L., Yang Y., Holloway P.H., Xue J., Solution-processed, nanostructured hybrid solar cells with broad spectral sensitivity and stability, Nanoscale, 2012, 4, 3507-3514. situ prepared nanoparticles and how it can be influenced to tune the interface between nanoparticles and polymer is almost unexplored up to now.

Altogether, it can be expected that the rapid development of in situ routes for the preparation of nanocomposites for hybrid solar cells will stay as dynamic in the future and by exploring new material combinations, and novel precursors in combination with optimized morphology and well-designed hybrid interfaces also further improvements in device performance will be achieved in near future.

\section{Acknowledgments}

Financial support by the Christian Doppler Research Association, the Austrian Federal Ministry of Economy, Family and Youth (BMWFJ), and ISOVOLTAIC AG is gratefully acknowledged.

[8] Jeltsch K.F., Schädel M., Bonekamp J.-B., Niyamakom P. Rauscher F., Lademann H.W.A., Dumsch I., Allard S., Scherf U., Meerholz K., Efficiency Enhanced Hybrid Solar Cells Using a Blend of Quantum Dots and Nanorods, Adv. Funct. Mater., 2012, 22, 397-404.

[9] Greenham N.C., Peng X, Alivisatos A.P., Charge separation and transport in conjugated-polymer/semiconductornanocrystal composites studied by photoluminescence quenching and photoconductivity, Phys. Rev. B, 1996, 54, 17628-17637.

[10] Huynh W.U., Dittmer J.J., Alivisatos A.P., Hybrid NanorodPolymer Solar Cells, Science, 2002, 295, 2425-2427.

[11] Zhou Y., Eck M., Krüger M., Bulk-heterojunction hybrid solar cells based on colloidal nanocrystals and conjugated polymers, Energy Environ. Sci., 2010, 3, 1851-1864.

[12] Saunders B.R., Turner M.L., Nanoparticle-polymer photovoltaic cells, Adv. Colloid Interface Sci., 2008, 138, 1-23.

[13] Saunders B.R., Hybrid polymer/nanoparticle solar cells: Preparation, principles and challenges, J. Colloid Interf. Sci., 2012, 369, 1-15.

[14] Zhou R., Xue J., Hybrid Polymer-Nanocrystal Materials for Photovoltaic Applications, Chem. Phys. Chem., 2012, 13, 2471-2480.

[15] Reiss P., Couderc E., De Girolamo J., Pron A., Conjugated polymers/semiconductor nanocrystals hybrid materials preparation, electrical transport properties and applications, Nanoscale, 2011, 3, 446-489.

[16] Skompska M., Hybrid conjugated polymer/semiconductor photovoltaic cells, Synth. Met., 2010, 160, 1-15.

[17] Wright M., Uddin A., Organic-inorganic hybrid solar cells: A comparative review, Sol. Energy Mater. Sol. Cells, 2012, 107, 87-111.

[18] Moulé A.J., Chang L., Thambidurai C., Vidu R., Stroeve P., Hybrid Solar Cells: basic principles and the role of ligands, J. Mater. Chem., 2012, 22, 2351-2368. 
[19] Zhao L., Lin Z., Crafting Semiconductor Organic-Inorganic Nanocomposites via Placing Conjugated Polymers in Intimate Contact with Nanocrystals for Hybrid Solar Cells, Adv. Mater., 2012, 24, 4353-4368.

[20] Tang W., Qu S., Teng F., Hou Y., Wang Y., Wang Z., Recent Developments of Hybrid Nanocrystal/Polymer Bulk Heterojunction Solar Cells, J. Nanosci. Nanotechnol., 2011, 11, 9384-9394.

[21] Wei H., Zhang H., Sun H., Yang B., Preparation of polymernanocrystals hybrid solar cells through aqueous approaches, Nano Today, 2012, 7, 316-326.

[22] Martinez-Ferrero E., Albero J., Palomares E., Materials, Nanomorphology, and Interfacial Charge Transfer Reactions in Quantum Dot/Polymer Solar Cell Devices, J. Phys. Chem. Lett., 2010, 1, 3039-3045.

[23] Helgesen M., Sondergaard R., Krebs F.C., Advanced materials and processes for polymer solar cell devices, J. Mater. Chem., 2010, 20, 36-60.

[24] Weickert J., Dunbar R.B., Hesse H.C., Wiedemann W., Schmidt-Mende L., Nanostructured organic and hybrid solar cells, Adv. Mater. 2011, 23, 1810-1828.

[25] Xu T., Qiao Q., Conjugated polymer-inorganic semiconductor hybrid solar cells, Energy Environ. Sci., 2011, 4, 2700-2720.

[26] Bashouti M., Lifshitz E., PbS Sub-micrometer Structures with Anisotropic Shape: Ribbons, Wires, Octapods, and Hollowed Cubes, Inorg. Chem., 2008, 47, 678-682.

[27] Sashchiuk A., Amirav L., Bashouti M., Krueger M., Sivan U., Lifshitz E., PbSe Nanocrystal Assemblies: Synthesis and Structural, Optical, and Electrical Characterization, Nano Lett., 2004, 4, 159-165.

[28] Alivisatos A.P.,Semiconductor Clusters, Nanocrystals, and Quantum Dots, Science, 1996, 271, 933-937.

[29] van Hal P.A., Wienk M.M., Kroon J.M., Verhees W.J.H., Slooff L.H., van Gennip W.J.H., Jonkheijm P., Janssen R.A.J., Photoinduced Electron Transfer and Photovoltaic Response of a MDMO-PPV:TiO, Bulk-Heterojunction, Adv. Mater., 2003, 15, 118-121.

[30] Oosterhout S.D., Wienk M.M., van Bavel S.S., Thiedmann R., Koster L.J.A., Gilot J., Loos J., Schmidt V., Janssen R.A.J., The effect of three-dimensional morphology on the efficiency of hybrid polymer solar cells, Nat. Mater., 2009, 8, 818-824.

[31] Reynolds L.X., Lutz T., Dowland S., MacLachlan A., King S., Haque S.A., Charge photogeneration in hybrid solar cells: a comparison between quantum dots and in situ grown CdS, Nanoscale, 2012, 4, 1561-1564, http://dx.doi.org/10.1039/ C2NR12081J.

[32] Zhou Y., Eck M., Men C., Rauscher F., Niyamakom P., Yilmaz S., Dumsch I., Allard S., Scherf U., Krüger M., Efficient polymer nanocrystal hybrid solar cells by improved nanocrystal composition, Sol. Energy Mater. Sol. Cells, 2011, 95, 3227-3232.

[33] Dayal S., Kopidakis N., Olson D.C., Ginley D.S., Rumbles G., Photovoltaic Devices with a Low Band Gap Polymer and CdSe Nanostructures Exceeding 3\% Efficiency, Nano Lett., 2010, 10, 239-242.
[34] Chen H.-C., Lai C.-W., Wu I.-C., Pan H.-R., Chen I.-W. P., Peng Y.-K., Liu C.-L., Chen C.-H., Chou P.-T., Enhanced Performance and Air Stability of 3.2\% Hybrid Solar Cells: How the Functional Polymer and CdTe Nanostructure Boost the Solar Cell Efficiency, Adv. Mater., 2011, 23, 5451-5455.

[35] Rath T., Edler M., Haas W., Fischereder A., Moscher S., Schenk A., Trattnig R., Sezen M., Mauthner G., Pein A., Meischler D., Bartl K., Saf R., Bansal N., Haque S.A., Hofer F., List E.J.W., Trimmel G., A Direct Route Towards Polymer/ Copper Indium Sulfide Nanocomposite Solar Cells, Adv. Energy Mater., 2011, 1, 1046-1050.

[36] Arici E., Hoppe H., Schäffler F., Meissner D., Malik M.A., Sariciftci N.S., Hybrid solar cells based on inorganic nanoclusters and conjugated polymers, Thin Solid Films, 2004, 451-452, 612-618.

[37] Cui D., Xu J., Zhu T., Paradee G., Ashok S., Gerhold M., Harvest of near infrared light in PbSe nanocrystal-polymer hybrid photovoltaic cells, Appl. Phys. Lett., 2006, 88, 183111.

[38] Tan F., Qu S., Wu J., Liu K., Zhou S., Wang Z., Preparation of $\mathrm{SnS}_{2}$ colloidal quantum dots and their application in organic/ inorganic hybrid solar cells, Nanoscale Res. Lett., 2011, 6, 298.

[39] Lin Y.-Y., Wang D.-W., Yen H.-C., Chen H.-L., Chen C.C., Chen C.-M., Tang C.-Y., Chen C.-W., Extended red light harvesting in a poly(3-hexylthiophene)/iron disulfide nanocrystal hybrid solar cell, Nanotechnology, 2009, 20, 405207.

[40] Martinez L., Bernechea M., Garcia de Arquer F.P., Konstantatos G., Near IR-Sensitive, Non-toxic, Polymer/ Nanocrystal Solar Cells Employing $\mathrm{Bi}_{2} \mathrm{~S}_{3}$ as the Electron Acceptor, Adv. Energy Mater., 2011, 1, 1029-1035.

[41] Liu C.Y., Holman Z.C., Kortshagen U.R., Optimization of Si NC/P3HT Hybrid Solar Cells, Adv. Funct. Mater., 2010, 20, 2157-2164.

[42] Huynh W.U., Dittmer J.J., Libby W.C., Whiting G.L., Alivisatos A.P., Controlling the Morphology of Nanocrystal-Polymer Composites for Solar Cells, Adv. Funct. Mater., 2003, 13, 7379.

[43] Radychev N., Lokteva I., Witt F., Kolny-Olesiak J., Borchert H., Parisi J., Physical Origin of the Impact of Different Nanocrystal Surface Modifications on the Performance of CdSe/P3HT Hybrid Solar Cells, J. Phys. Chem. C, 2011, 115, 14111-14122.

[44] Greaney M.J., Das S., Webber D.H., Bradforth S.E., Brutchey R.L., Improving Open Circuit Potential in Hybrid P3HT:CdSe Bulk Heterojunction Solar Cells via Colloidal tert-Butylthiol Ligand Exchange, ACS Nano, 2012, 6, 4222-4230.

[45] Webber D.H., Brutchey R.L., Ligand Exchange on Colloidal CdSe Nanocrystals Using Thermally Labile tert-Butylthiol for Improved Photocurrent in Nanocrystal Films, J. Am. Chem. Soc., 2012, 134, 1085-1092.

[46] Seo J., Kim W.J., Kim S.J., Lee, K.-S., Cartwright A.N., Prasad P.N., Polymer nanocomposite photovoltaics utilizing CdSe nanocrystals capped with a thermally cleavable solubilizing ligand, Appl. Phys. Lett., 2009, 94, 133302. 
[47] Antoun T., Brayner R., Al Terary S., Fiévet F., Chehimi M., Yassar A., Facile Synthesis of Oligothiophene-Capped CdS Nanoparticles, Eur. J. Inorg. Chem., 2007, 12751284.

[48] Locklin J., Patton D., Deng S., Baba A., Millan M., Advincula R.C., Conjugated Oligothiophene-Dendron-Capped CdSe Nanoparticles: Synthesis and Energy Transfer, Chem. Mater., 2004, 16, 5187-5193.

[49] Watt A.A.R., Meredith P., Riches J.D., Atkinson S., Rubinsztein-Dunlop H., A PbS quantum-cube: conducting polymer composite for photovoltaic applications, Curr. Appl. Phys., 2004, 4, 320-322.

[50] Zhou Y., Riehle F.S., Yuan Y., Schleiermacher H.-F., Niggemann M., Urban G.A., Krüger M., Improved efficiency of hybrid solar cells based on non-ligand-exchanged CdSe quantum dots and poly(3-hexylthiophene), Appl. Phys. Lett., 2010, 96, 013304-1-3.

[51] Williams S.S., Hampton M.J., Gowrishankar V., Ding I.-K., Templeton J.L., Samulski E.T., DeSimone J.M., McGehee M.D., Nanostructured Titania-Polymer Photovoltaic Devices Made Using PFPE-Based Nanomolding Techniques, Chem. Mater., 2008, 20, 5229-5234.

[52] Coakley K.M., McGehee D., Photovoltaic cells made from conjugated polymers infiltrated into mesoporous titania, Appl. Phys. Lett., 2003, 83, 3380-1-3.

[53] Gershon T., Metal oxide applications in organic-based photovoltaics, Mater. Sci Techn., 2011, 27, 1357-1371.

[54] Boucle J., Ravirajan P., Nelson J., Hybrid polymer-metal oxide thin films for photovoltaic applications, J. Mater. Chem., 2007, 17, 3141-3153.

[55] Boucle J., Ackermann J., Solid State dye sensitized and bulk heterojunction solar cells using $\mathrm{TiO}_{2}$ and $\mathrm{ZnO}$ nanostructures: recent progress and new concepts at the borderline, Polym. Int., 2012, 61, 355-373.

[56] Slooff L.H., Wienk M.M., Kroon J.M., Hybrid $\mathrm{TiO}_{2}$ :polymer photovoltaic cells made from a titanium oxide precursor, Thin Solid Films, 2004, 451-452, 634-638.

[57] Slooff L.H., Kroon J.M., Loos J., Koetse M.M., Sweelssen J., Influence of the Relative Humidity on the Performance of Polymer/TiO 2 Photovoltaic Cells, Adv. Funct. Mater., 2005, 15, 689-694.

[58] Haeldermans I., Vandewal K., Oosterbaan W.D., Gadisa A., D'Haen J., Van Bael M.K., Manca J.V., Mullens J., Groundstate charge-transfer complex formation in hybrid poly(3hexyl thiophene):titanium dioxide solar cells, Appl. Phys. Lett., 2008, 93, 223302-1-3.

[59] Barlier V., Bounor-Legare V., Alcouffe P., Boiteux G., Davenas J., Formation of $\mathrm{TiO}_{2}$ domains in Poly(9-vinylcarbazole) thin film by hydrolysis-condensation of a metal alkoxide, Thin Solid Films, 2007, 515, 6328-6331.

[60] Barlier V., Bounor-Legare V., Boiteux G., Leonard D., Davenas J., $\mathrm{TiO}_{2}$ :polymer bulk-heterojunction thin films made from a miscible new carbazole based $\mathrm{TiO}_{2}$ precursor with poly $(\mathrm{N}$ vinylcarbazole) for enhanced charge transfer properties, Mater. Chem. Phys., 2009, 115, 429-433.
[61] Barlier V., Bounor-Legare V., Boiteux G., Davenas J., Slazak A., Rybak A., Jung J., Photogeneration and photovoltaic effect in poly(N-vinylcarbazole): $\mathrm{TiO}_{2}$ bulkheterojunction elaborated by hydrolysis-condensation reactions of $\mathrm{TiO}_{2}$ precursors, Synth. Metals, 2009, 159, 508-512.

[62] Chang Y.-M., Su W.-F., Wang L., Photoactive Polythhiophene:Titania Hybrids with Excellent Miscibility for Use in Polymer Photovoltaic Cells, Macromol. Rapid Commun., 2008, 29, 1303-1308.

[63] Chen H.-J., Wang L., Chiu W.-Y., Effects of annealing treatment on the properties of MEH-PPV/titania hybrids via in situ sol-gel reaction, Europ. Polym. J., 2007, 43, 4750-4761.

[64] Chen H.-J., Wang L., Chiu W.-Y., Preparation of MEH-PPV/ Nanosized Titania Hybrids Via In Situ Sol-Gel Reaction of Titanium Alkoxide: Optical Property, J. Polym Sci. A: Polym. Chem., 2008, 46, 515-529.

[65] Lin C.-L., Yeh M.-Y., Chen C. H., Sudhakar S., Luo S.-J., Hsu Y.-C., Huang C.-Y., Ho K.-C., Luh T.-Y., Silica-TitaniaBased Organic-Inorganic Hybrid Materials for Photovoltaic Applications, Chem. Mater., 2006, 18, 4157-4162.

[66] Wang M., Wang X., PPV/TiO 2 hybrid composites prepared from PPV precursor reaction in aqueous media and their application in solar cells, Polymer, 2008, 49, 1587-1593.

[67] Neyshtadt S., Kalina M., Frey G.L., Self-Organized Semiconducting Polymer-Incorporated Mesostructured Titania for Photovoltaic Applications, Adv. Mater., 2008, 20, 2541-2546.

[68] Neyshtadt S., Jahnke J.P., Messinger R.J., Rawal A., Segal Peretz T., Huppert D., Chmelka B.F., Frey G.L., Understanding and Controlling Organic-Inorganic Interfaces in Mesostructured Hybrid Photovoltaic Materials, J. Am. Chem. Soc., 2011, 133, 10119-10133.

[69] Huang J., Yin Z., Zheng Q., Applications of ZnO in organic and hybrid solar cells, Energy Environ. Sci., 2011, 4, 38613877.

[70] Beek W.J.E., Sloof L.H., Wienk M.M., Kroon J.M., Janssen, R.A.J., Hybrid Solar Cells Using a Zinc Oxide Precursor and a Conjugated Polymer, Adv. Funct. Mater., 2005, 15, 17031707.

[71] Beek W.J.E., Wienk M.M., Janssen R.A.J., Efficient Hybrid Solar Cells from Zinc Oxide Nanoparticles and a Conjugated Polymer, Adv. Mater., 2004, 16, 1009-1013.

[72] Moet D.J.D., Koster L.J.A., de Boer B., Blom P.W.M., Hybrid Polymer Solar Cells from Highly Reactive Diethylzinc: MDMO-PPV versus P3HT, Chem. Mater., 2007, 19, 58565861.

[73] Stenzel O., Koster L.J.A., Thiedmann R., Oosterhout S.D., Janssen R.A.J., Schmidt V., A New Approach to ModelBased Simulation of Disordered Polymer Blend Solar Cells, Adv. Funct. Mater., 2012, 22, 1236-1244.

[74] Oosterhout S.D., Koster L.J.A., van Bavel S.S., Loos J., Stenzel O., Thiedmann R., Schmidt V., Campo B., Cleij T.J., Lutzen L., Vanderzande D., Wienk M.M., Janssen R.A.J., Controlling the Morphology and Efficiency of 
Hybrid ZnO:Polythiophene Solar Cells Via Side Chain Functionalization, Adv. Energy Mater., 2011, 1, 90-96.

[75] Oosterhout S.D., Wienk, M.M., Al-Hashimi M., Heeney M., Janssen R.A.J., Hybrid Polymer Solar Cells from Zinc Oxide and Poly-(3-hexylselenophene), J. Phys. Chem C., 2011, 115, 18901-18908.

[76] Han S.J., Adikaari A.A.D.T., Jayawardena K.D.G.I., Nismy N.A., Silva S.R.P., Control of nanocrystal surface defects for efficient charge extraction in polymer-ZnO photovoltaic systems, J. Appl. Phys., 2012, 112, 066103-1-3.

[77] Peng X., Zhang L., Chen Y., Li F., Zhou W., In situ preparation and fluorescence quenching properties of polythiophene/ $\mathrm{ZnO}$ nanocrystals hybrids through atom-transfer radical polymerization and hydrolysis, Appl. Surf. Sci., 2010, 256, 2948-2955.

[78] Yuan K., Li F., Chen L., Chen Y., Approach to a block polymer precursor from poly(3-hexylthiophene)nitroxide-mediated in situ polymerization for stabilization of poly(3-hexylthiophene)/ ZnO hybrid solar cells, Thin Solid Films, 2012, 520, 62996306.

[79] Yuan K., Li F., Chen Y., Wang X., Chen L., In-situ growth nanocomposites composed of rodlike $\mathrm{ZnO}$ nanocrystals arranged by nanoparticles in a self-assembling diblock copolymer for heterojunction optoelectronics, J. Mater. Chem., 2011, 21, 11886-11894.

[80] Lai C.-H., Lee W.-F., Wu I.-C., Kang C.-C., Chen D.-Y., Chen L.-J., Chou P.-T., Highly luminescent, homogeneous $\mathrm{ZnO}$ nanoparticles synthesized via semiconductive polyalkyloxythiophene template, J. Mater. Chem., 2009, 19, 7284-7289

[81] Wang M., Lian Y., Wang X., PPV/PVA/ZnO nanocomposite prepared by complex precursor method and its photovoltaic application, Curr. Appl. Phys., 2009, 9, 189-194.

[82] Liu G., Yin L.-C., Wang J., Niu P., Zhen C., Xie Y., Cheng H.-M., A red anatase $\mathrm{TiO}_{2}$ photocatalyst for solar energy conversion, Energy Environ. Sci., 2012, 5, 9603-9610.

[83] Chen W., Chen Y., Li F., Chen L., Yuan K., Yao K., Wang P., Ordered microstructure induced by orientation behavior of liquid-crystal polythiophene for performance improvement of hybrid solar cells, Sol. Energy Mater. Sol. Cells, 2012, 96, 266-275.

[84] Schockley W., Queisser H.J., Detailed Balance Limit of Efficiency of p-n Junction Solar Cells, J. Appl. Phys., 1961, 32, 510-519.

[85] Dhage S.R., Colorado H.A., Hahn T., Morphological variations in cadmium sulfide nanocrystals without phase transformation, Nanoscale Res. Lett., 2011, 6, 420-1-5.

[86] JasieniakJ., Califano M., Watkins S.E., Size-Dependent Valence and Conduction Band-Edge Energies of Semiconductor Nanocrystals, ACS Nano, 2011, 5, 5888-5902.

[87] Arici E., Sariciftci N.S., Meissner D., Hybrid Solar Cells Based on Nanoparticles of CulnS, in Organic Matrices, Adv. Funct. Mater., 2003, 13, 165-171.

[88] Watt A., Thomsen E., Meredith P., Rubinsztein-Dunlop H., A new approach to the synthesis of conjugated polymer- nanocrystal composites for heterojunction optoelectronics, Chem. Commun., 2004, 2334-2335.

[89] Watt A., Rubinsztein-Dunlop H., Meredith P., Growing semiconductor nanocrystals directly in a conducting polymer, Mater. Lett., 2005, 59, 3033-3036.

[90] Warner J.H., Watt A.A.R., Monodisperse PbS nanocrystals synthesized in a conducting polymer, Mater. Lett., 2006, 60, 2375-2378.

[91] Watt A.A.R., Blake D., Warner J.H., Thomsen E.A., Tavenner E.L., Rubinsztein-Dunlop H., Meredith P., Lead sulfide nanocrystal: conducting polymer solar cells, J. Phys. D: Appl. Phys., 2005, 38, 2006-2012.

[92] Watt A., Eichmann T., Rubinsztein-Dunlop H., Meredith P., Carrier transport in $\mathrm{PbS}$ nanocrystal conducting polymer composites, Appl. Phys. Lett., 2005, 87, 253109-1-3.

[93] Stavrinadis A., Beal R., Smith J.M., Assender H.E., Watt A.A.R., Direct Formation of PbS Nanorods in a Conjugated Polymer, Adv. Mater., 2008, 20, 3105-3109.

[94] Stavrinadis A., Xu S., Warner J.H., Hutchison J.L., Smith J.M., Watt A.A.R., Superstructures of PbS nanocrystals in a conjugated polymer and the aligning role of oxidation, Nanotechnology, 2009, 20, 445608-1-7.

[95] Liao H.-C., Chen S.-Y., Liu D.-M., In-Situ Growing CdS SingleCrystal Nanorods via P3HT Polymer as a Soft Template for Enhancing Photovoltaic Performance, Macromolecules, 2009, 42, 6558-6563.

[96] Liao H.-C., Chantarat N., Chen S.-Y., Peng C.-H., Annealing Effect on Photovoltaic Performance of Hybrid P3HT/In-Situ Grown CdS Nanocrystal Solar Cells, J. Electrochem. Soc., 2011, 158, E67-E72.

[97] Sonar P., Sreenivasan K.P., Maddanimath T., Vijayamohanan K., Comparative behavior of CdS and CdSe quantum dots in poly(3-hexylthiophene) based nanocomposites, Mater. Res. Bull., 2006, 41, 198-208.

[98] Dayal S., Kopidakis N, Olson D.C., Ginley D.S., Rumbles G., Direct Synthesis of CdSe Nanoparticles in Poly(3hexylthiophene), J. Am. Chem. Soc., 2009, 131, 17726-17727.

[99] Sun, B., Greenham, N.C., Improved Efficiency of Photovoltaics Based on CdSe Nanorods and Poly(3-hexylthiophene) Nanofibers, Phys. Chem. Chem. Phys., 2006, 8, 3557-3560.

[100] Wu Y., Zhang G., Performance Enhancement of Hybrid Solar Cells Through Chemical Vapor Annealing, Nano Lett., 2010, 10, 1628-1631.

[101] Antolini F., Pentimalli M., Di Luccio T., Terzi R., Schioppa M., Re M., Mirenghi L., Tapfer L., Structural characterization of CdS nanoparticles grown in polystyrene matrix by thermolytic synthesis, Mater. Lett., 2005, 59, 3181-3187.

[102] Antolini F., Burresi E., Stroea L., Morandi V., Ortolani L. Accorsi G., Blosi M., Time and Temperature Dependence of CdS Nanoparticles Grown in a Polystyrene Matrix, J. Nanomater., 2012, 815696, 1-11.

[103] Resta V., Laera A.M., Piscopiello E., Schioppa M., Tapfer L., Highly Efficient Precursors for Direct Synthesis of Tailored CdS Nanocrystals in Organic Polymers, J. Phys. Chem. C, 2010, 114, 17311-17317. 
[104] Boriello C., Masala S., Bizzarro V., Nenna G., Re M., Pesce E., Minarini C., Di Luccio T., Electroluminescence properties of poly(3-hexylthiophene)-cadmium sulfide nanoparticles grown in situ, J. Appl. Polym. Sci., 2011, 122, 3624-3629.

[105] Masala S., Del Gobbo S., Borriello C., Bizzarro V., La Ferrara V., Re M., Pesce E., Minarini C., De Crescenzi M., Di Luccio T., Hybrid polymer-CdS solar cell active layers formed by in situ growth of CdS nanoparticles, J. Nanopart. Res., 2011, 13, 6537-6544.

[106] Laera A.M., Resta V., Ferrara M.C., Schioppa M., Piscopiello E., Tapfer L., Synthesis of hybrid organic-inorganic nanocomposite materials based on CdS nanocrystals for energy conversion applications, J. Nanopart. Res., 2011, 13, 5705-5717.

[107] Bhardwaj R.K., Kushwaha H.S., Gaur J., Upreti T., Bharti V., Gupta V., Chaudhary N., Sharma G.D., Banerjee K., Chand S., A green approach for direct growth of CdS nanoparticles network in poly(3-hexylthiophene-2,5-diyl) polymer film for hybrid photovoltaic, Mater. Lett., 2012, 89, 195-197.

[108] De Freitas J.N., Grova I.R., Akcelrud L.C., Arici E., Sariciftci N.S., Nogueira A.F., The effects of CdSe incorporation into bulk heterojunction solar cells, J. Mater. Chem., 2010, 20, 4845-4853.

[109] Khan M.T., Kaur A., Dhawan S.K., Chaud S., In-Situ growth of cadmium telluride nanocrystals in poly(3-hexylthiophene) matrix for photovoltaic application, J. Appl. Phys., 2011, 110, 044509-1-7.

[110] Kwak E.-J., Woo S., Lee H., Kim H., Kim, Y., Hybrid Solar Cells with In-Situ Prepared Inorganic Nanoparticles/Polymer Bulk Heterojunction Films, J. Nanoelectron. Optoe., 2012, 7 , 434-438.

[111] Maier E., Haas W., Santis-Alvarez A.J., Rath T., Hofer F., Stelzer F., Trimmel G., Polymer - CulnS 2 hybrid solar cells obtained by an in-situ formation route, Conference Record of the 35th IEEE Photovoltaic Specialists Conference, 2010, 3365-3368.

[112] Katz E.A., Gevorgyan S., Orynbayev M.S., Krebs F.C., Outdoor testing and long-term stability of plastic solar cells, Eur. Phys. J. Appl. Phys., 2007, 36, 307-311.

[113] Maier E., Fischereder A., Haas W., Mauthner G., Albering J., Rath T., Hofer F., List E.J.W., Trimmel G., Metal sulfidepolymer nanocomposite thin films prepared by a direct formation route for photovoltaic applications, Thin Solid Films, 2011, 519, 4201-4206.

[114] Maier E., Rath T., Haas W., Werzer O., Saf R., Hofer F., Meissner D., Volobujeva O., Bereznev S., Mellikov E., Amenitsch H., Resel R., Trimmel G., CulnS 2 -Poly(3(ethyl-4-butanoate)thiophene) nanocomposite solar cells: Preparation by an in situ formation route, performance and stability issues, Sol. Energy Mater. Sol. Cells, 2011, 95, 1354-1361.

[115] Gruber M., Stickler B.A., Trimmel G., Schürrer F., Zojer K., Impact of energy alignment and morphology on the efficiency in inorganic-organic hybrid solar cells, Org. Electronics, 2010, 11, 1999-2011.
[116] Stickler B.A., Gruber M., Trimmel G., Schürrer F., Zojer K., Influence of transport-related material parameters on the I-V characteristic of inorganic-organic hybrid solar cells, Org. Electronics, 2011, 12, 1434-1445.

[117] Leventis H.C., King S.P., Sudlow A., Hill M.S., Molloy K.C., Haque S.A., Nanostructured Hybrid Polymer-Inorganic Solar Cell Active Layers Formed by Controllable in Situ Growth of Semiconducting Sulfide Networks, Nano Lett., 2010, 10, $1253-1258$.

[118] Dowland S., Lutz T., Ward A., King S.P., Sudlow A., Hill M.S., Molloy K.C., Haque S.A., Direct growth of metal sulfide nanoparticle networks in solid-state polymer films for hybrid inorganic-organic solar cells, Adv. Mater., 2011, 23, 27392744.

[119] Krebs F.C., Tromholt T., Jorgensen M., Upscaling of polymer solar cell fabrication using full roll-to-roll processing, Nanoscale, 2010, 2, 873-886.

[120] DePuy C.H., King R.W., Pyrolytic Cis Eliminations, Chem. Rev., 1960, 60, 431-457.

[121] Arar M., Pein A., Haas W., Hofer F., Norrman K., Krebs F.C., Rath T., Trimmel G., Comprehensive Investigation of Silver Nanoparticle/Aluminum Electrodes for Copper Indium Sulfide/Polymer Hybrid Solar Cells, J. Phys. Chem. C, 2012, 116, 19191 - 19196.

[122] Rath T., Kaltenhauser V., Haas W., Reichmann A., Hofer F., Trimmel G., Solution-processed small molecule/copper indium sulfide hybrid solar cells, Sol. Energy Mater. Sol. Cells, 2013, 114, 38-42.

[123] Yang J., Tang A., Zhou R., Xue J., Effects of nanocrystal size and device aging on performance of hybrid poly(3hexylthiophene):CdSe nanocrystal solar cells, Sol. Energy Mater. Sol. Cells, 2011, 95, 476-482.

[124] Fu W., Shi Y., Quu W., Wang L., Nan Y., Shi M., Li H., Chen H., High efficiency hybrid solar cells using post-deposition ligand exchange by monothiols, Phys. Chem. Chem. Phys., 2012, 14, 12094-12098.

[125] Jia J., He W., Chen X., Lei Y., Zheng Z., In situ fabrication of chalcogenide nanoflake arrays for hybrid solar cells: the case of $\ln _{2} \mathrm{~S}_{3} /$ poly(3-hexylthiophene), J. Mater. Chem., 2011, 21, 12824-12828.

[126] Lei Y., Jia H., He W., Zhang Y, Mi L., Hou H., Zhu G., Zheng Z., Hybrid Solar Cells with Outstanding Short-Circuit Currents Based on a Room Temperature Soft-Chemical Strategy: The Case of P3HT:Ag S, J. Am. Chem. Soc., 2012, 134, 1739217395.

[127] Li Y., Zhang Y., Lei Y., Li P., Jia H., Hou H., Zheng Z., In situ fabrication of $\mathrm{Bi}_{2} \mathrm{~S}_{3}$ nanocrystal film for photovoltaic devices, Mater. Sci. Eng. B, 2012, 177, 1764-1768.

[128] Zhang Y., Wang C., Rothberg L., Ng M.-K.,Surface-initiated growth of conjugated polymers for functionalization of electronically active nanoporous networks: synthesis, structure and optical properties, J. Mater. Chem., 2006, 16, 3721-3725.

[129] Lu S., Sun S.-S., Jiang X., Mao J., Li T., Wan K., In situ 3-hexylthiophene polymerization onto surface of $\mathrm{TiO}_{2}$ based 
hybrid solar cells, J. Mater. Sci. Mater. Electron., 2010, 21, 682-686.

[130] Tepavcevic S., Darling S.B., Dimitrijevic N.M., Rajh T., Sibener S.J., Improved Hybrid Solar Cells via in situ UV Polymerization, Small, 2009, 5, 1776-1783.

[131] Atienzar P., Ishwara T., Horie M., Durrant J.R., Nelson J., Hybrid polymer-metal oxide solar cells by in situ chemical polymerization, J. Mater. Chem., 2009, 19, 5377-5380.

[132] Mejía M.L., Agapiou K., Yang X., Holliday B.J., Seeded Growth of CdS Nanoparticles within a Conducting Metallopolymer Matrix, J. Am. Chem. Soc., 2009, 131, 18196-18197.

[133] Roux S., Soler-llia G.J.A.A., Demoustier-Champagne S., Audebert P., Sanchez C., Titania/Polypyrrole Hybrid Nanocomposites Built from In-Situ Generated Organically
Functionalized Nanoanatase Building Blocks, Adv. Mater., 2003, 15, 217-221.

[134] Xiong S., Phua S.L., Dunn B.S., Ma J., Lu X., Covalently bonded Polyaniline- $\mathrm{TiO}_{2}$ Hybrids: A Facile Approach to Highly Stable Anodic Electrochromic Materials with Low Oxidation Potential, Chem. Mater., 2010, 22, 255-260.

[135] Skaff H., Sill K., Emrick T., Quantum Dots Tailored with Poly(para-phenylenevinylene), J. Am. Chem. Soc., 2004, 126, 11322-11325.

[136] Kanelidis I., Vaneski A., Lenkeit D., Pelz S., Elsner V., Stewart R.M., Rodríguez-Fernández J., Lutich A.A.. Susha A. S, Theissmann R., Adamczyk S., Rogach A.L., Holder E., Inorganic-organic nanocomposites of CdSe nanocrystals surface-modified with oligo- and poly(fluorene) moieties, J. Mater. Chem., 2011, 21, 2656-2662. 